Washington University School of Medicine Digital Commons@Becker

Open Access Publications

2019

\title{
RAG-mediated DNA breaks attenuate PU.1 activity in early B cells through activation of a SPIC-BCLAF1 complex
}

\author{
Deepti Soodgupta \\ Washington University School of Medicine in St. Louis \\ Lynn S. White \\ Washington University School of Medicine in St. Louis \\ Wei Yang \\ Washington University School of Medicine in St. Louis \\ Rachel Johnston \\ Washington University School of Medicine in St. Louis \\ Jared M. Andrews \\ Washington University School of Medicine in St. Louis
}

See next page for additional authors

Follow this and additional works at: https://digitalcommons.wustl.edu/open_access_pubs

Please let us know how this document benefits you.

\section{Recommended Citation}

Soodgupta, Deepti; White, Lynn S.; Yang, Wei; Johnston, Rachel; Andrews, Jared M.; Kohyama, Masako; Murphy, Kenneth M.; Mosammaparast, Nima; Payton, Jacqueline E.; and Bednarski, Jeffrey J., "RAGmediated DNA breaks attenuate PU.1 activity in early B cells through activation of a SPIC-BCLAF1 complex." Cell Reports. 29, 4. 829 - 843.e5. (2019).

https://digitalcommons.wustl.edu/open_access_pubs/8437

This Open Access Publication is brought to you for free and open access by Digital Commons@Becker. It has been accepted for inclusion in Open Access Publications by an authorized administrator of Digital Commons@Becker. For more information, please contact vanam@wustl.edu. 


\section{Authors}

Deepti Soodgupta, Lynn S. White, Wei Yang, Rachel Johnston, Jared M. Andrews, Masako Kohyama, Kenneth M. Murphy, Nima Mosammaparast, Jacqueline E. Payton, and Jeffrey J. Bednarski 


\section{Cell Reports}

\section{RAG-Mediated DNA Breaks Attenuate PU.1 Activity in Early B Cells through Activation of a SPIC-BCLAF1 Complex}

\section{Graphical Abstract}

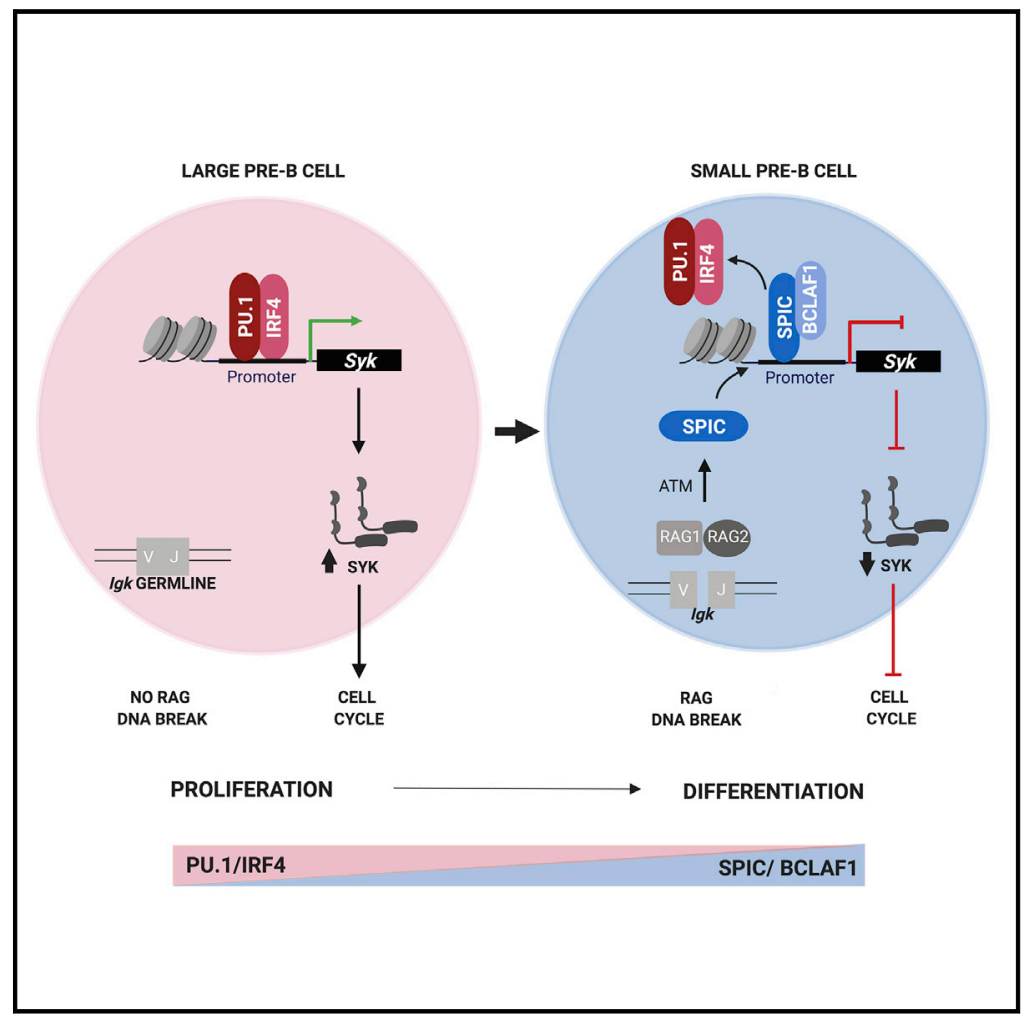

Highlights

- RAG DNA breaks upregulate SPIC, which induces genomewide changes in PU.1 activity

- SPIC binds to gene-regulatory elements, resulting in loss of PU.1 at these regions

- SPIC complexes with BCLAF1 to suppress transcription in response to RAG DNA breaks

- SPIC/BCLAF1 inhibits SYK and promotes transition from large to small pre-B cells

\section{Authors}

Deepti Soodgupta, Lynn S. White, Wei Yang, ..., Nima Mosammaparast, Jacqueline E. Payton, Jeffrey J. Bednarski

Correspondence

bednarski_j@wustl.edu

\section{In Brief}

ETS-family transcription factors are key regulators of early $B$ cell development. Soodgupta et al. show that RAG-induced DNA breaks generated during antigen receptor gene recombination activate a SPIC/BCLAF1 transcription factor complex that counters PU.1 activity and regulates gene expression changes to promote transition from large to small pre-B cells. 


\title{
RAG-Mediated DNA Breaks Attenuate PU.1 Activity in Early B Cells through Activation of a SPIC-BCLAF1 Complex
}

\author{
Deepti Soodgupta, ${ }^{1}$ Lynn S. White, ${ }^{1}$ Wei Yang, ${ }^{2}$ Rachel Johnston, ${ }^{1}$ Jared M. Andrews, ${ }^{3}$ Masako Kohyama, ${ }^{4}$ \\ Kenneth M. Murphy, ${ }^{3}$ Nima Mosammaparast, ${ }^{3}$ Jacqueline E. Payton, ${ }^{3}$ and Jeffrey J. Bednarski ${ }^{1,5, *}$ \\ ${ }^{1}$ Department of Pediatrics, Washington University School of Medicine, St. Louis, MO 63110, USA \\ 2Department of Genetics, Washington University School of Medicine, St. Louis, MO 63110, USA \\ ${ }^{3}$ Department of Pathology and Immunology, Washington University School of Medicine, St. Louis, MO 63110, USA \\ ${ }^{4}$ Department of Immunochemistry, Research Institute for Microbial Diseases, Osaka University, Suita, Osaka 565-0871, Japan \\ 5Lead Contact \\ *Correspondence: bednarski_j@wustl.edu \\ https://doi.org/10.1016/j.celrep.2019.09.026
}

\section{SUMMARY}

Early $\mathrm{B}$ cell development is regulated by stage-specific transcription factors. PU.1, an ETS-family transcription factor, is essential for coordination of early $B$ cell maturation and immunoglobulin gene $(I g)$ rearrangement. Here we show that RAG DNA doublestrand breaks (DSBs) generated during /g light chain gene (Igl) rearrangement in pre-B cells induce global changes in PU.1 chromatin binding. RAG DSBs activate a SPIC/BCLAF1 transcription factor complex that displaces PU.1 throughout the genome and regulates broad transcriptional changes. SPIC recruits BCLAF1 to gene-regulatory elements that control expression of key $B$ cell developmental genes. The SPIC/BCLAF1 complex suppresses expression of the SYK tyrosine kinase and enforces the transition from large to small pre-B cells. These studies reveal that RAG DSBs direct genome-wide changes in ETS transcription factor activity to promote early $B$ cell development.

\section{INTRODUCTION}

B cell development requires the sequential assembly and expression of genes encoding the immunoglobin heavy (Igh) and immunoglobulin light (Igl) chains to generate a mature B cell receptor (BCR) (Rajewsky, 1996). Ig genes are assembled through the process of $V(D) J$ recombination, which joins distant variable $(\mathrm{V})$, joining $(\mathrm{J})$, and diversity $(\mathrm{D})$ segments (Fugmann et al., 2000). The DNA double-strand breaks (DSBs) necessary for $V(D) J$ recombination are generated by the RAG endonuclease, which is composed of the RAG1 and RAG2 proteins (Fugmann et al., 2000). RAG-mediated DNA breaks are generated in the G1 phase of the cell cycle and activate the DNA damage response (DDR) kinase ATM, which facilitates repair of the broken DNA ends through nonhomologous end joining (Helmink and Sleckman, 2012). In response to RAG DSBs, ATM also activates a broad transcriptional program that regulates genes involved in diverse B cell functions, including migration, cell-cycle arrest, survival, and differentiation (Bednarski et al., 2012, 2016; Bredemeyer et al., 2008; Helmink and Sleckman, 2012; Steinel et al., 2013). This genetic program is mediated by ATMdependent activation of several transcription factors, including NF-KB1, NF-KB2, and SPIC (Bednarski et al., 2012, 2016; Bredemeyer et al., 2008).

The lgh gene is assembled first in pro-B cells and productive rearrangement results in its surface expression with surrogate light chains ( $\lambda 5$ and VpreB) to generate the pre-BCR, which signals transition to the large pre-B cell stage (Clark et al., 2014; Herzog et al., 2009; Rajewsky, 1996). Pre-BCR oligomerization signals through the SYK tyrosine kinase to promote proliferation and clonal expansion of large pre-B cells (Clark et al., 2014; Herzog et al., 2009). Activation of SYK also triggers $I g I_{\kappa}(I g k)$ gene recombination (Clark et al., 2014). RAG expression is suppressed in proliferating cells, and as such, lgk gene assembly requires induction of cell-cycle arrest and transition to the small, non-proliferating pre-B cell stage (Clark et al., 2014; Desiderio et al., 1996; Johnson et al., 2008; Ochiai et al., 2012). RAG DSBs activate ATM-dependent DDR signaling pathways that enforce cell-cycle arrest and promote survival to prevent proliferation of cells with unrepaired DSBs and permit time for proper assembly of Igk genes (Bednarski et al., 2012, 2016; DeMicco et al., 2016).

B cell development and assembly of $I g$ genes are carefully orchestrated by developmental stage-specific transcription factors, including E2A, EBF, Pax5, PU.1 and SPIB (Pang et al., 2014). The ETS-family transcription factor PU. 1 is required for $B$ cell lineage commitment and is constitutively expressed throughout B cell development (Polli et al., 2005; Schweitzer and DeKoter, 2004; Scott et al., 1994, 1997). PU.1 has critical functions during B cell maturation. In pre-B cells, PU.1 regulates expression of a diverse genetic program, including genes involved in B cell proliferation, differentiation, and $/ g$ gene rearrangement (Batista et al., 2017; Heinz et al., 2010; Solomon et al., 2015). Expression of SYK and germline transcription of Igk, which are required for pre-BCR signaling and initiating $\mathrm{V}(\mathrm{D})$ $\mathrm{J}$ recombination, respectively, depend on PU.1 activity (Batista et al., 2017; Herzog et al., 2009; Schwarzenbach et al., 1995; Schweitzer and DeKoter, 2004). Interestingly, loss of PU.1 in B 
A
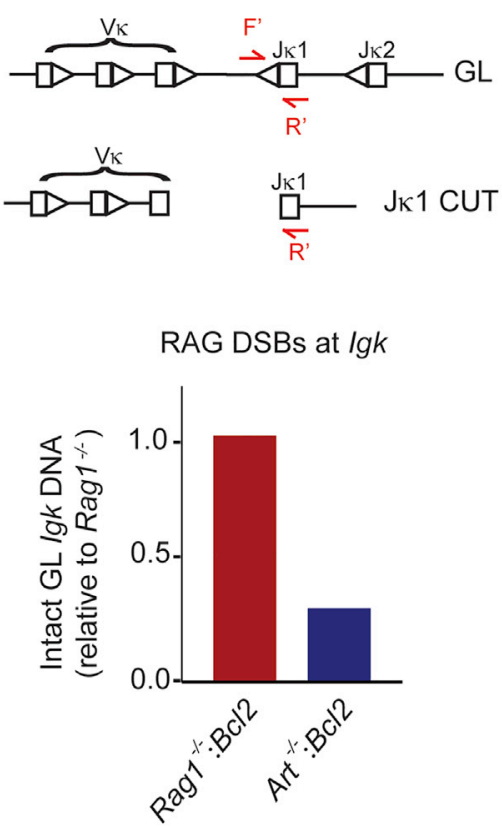

B

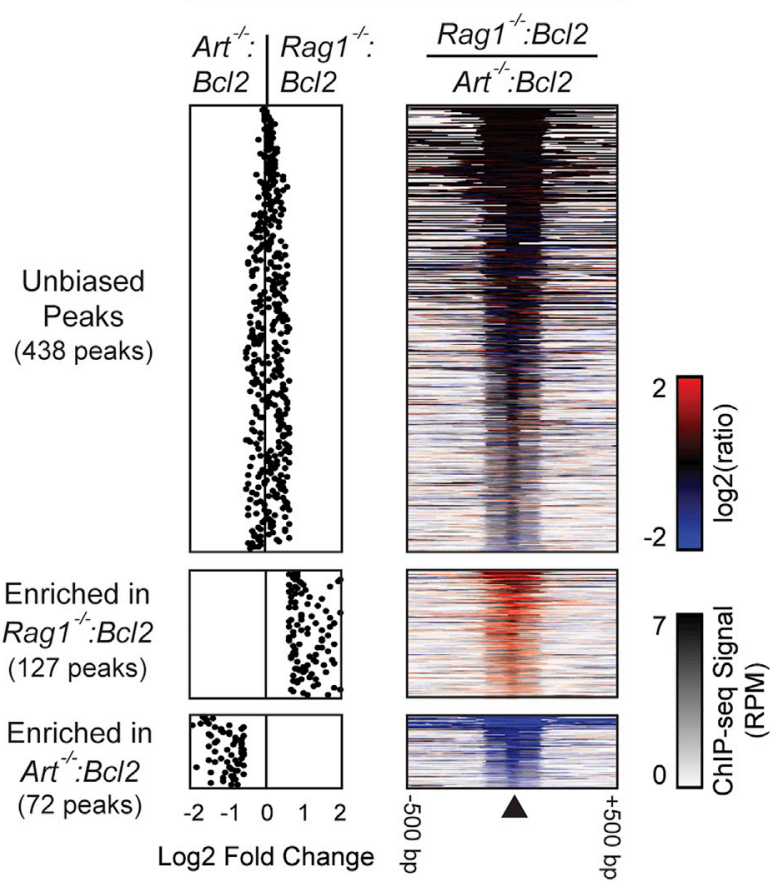

C
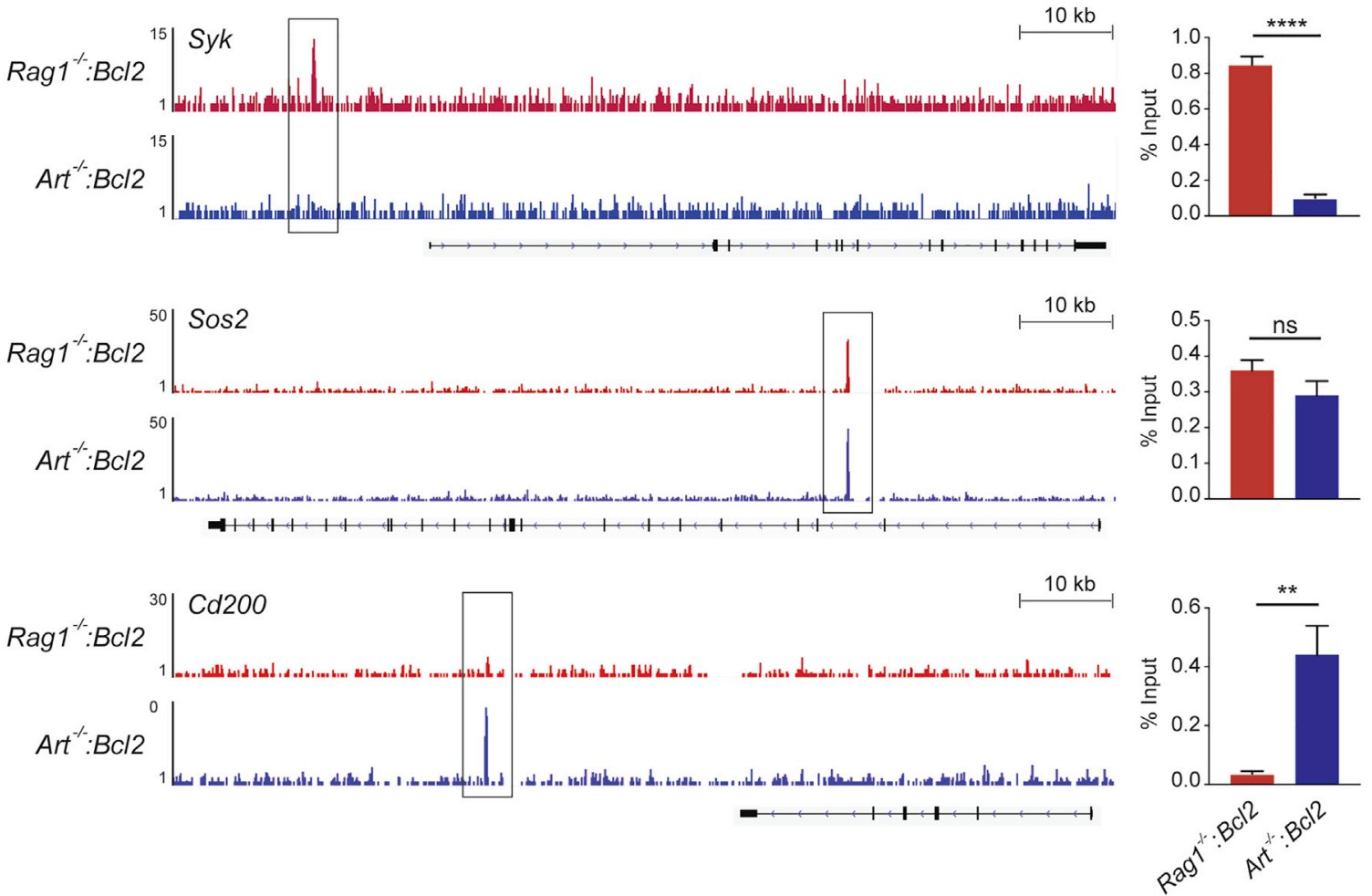

Figure 1. RAG DSB Signals Induce Genome-wide Changes in PU.1 Binding

(A) qPCR analysis of $/ g k$ genomic DNA from Rag $^{-1-}: B c / 2$ (red) and $A{ }^{-1-}: B c / 2$ (blue) abl pre-B cells treated with imatinib for $48 \mathrm{~h}$. Schematic shows germline (GL) Igk locus and unrepaired $\mathrm{J} \kappa 1$ coding end with location of PCR primers. PCR is normalized to Rag $1^{-1-}: B c / 2$ abl pre-B cells, which do not generate RAG DSBs and have only intact germline Igk DNA. Data are representative of three independent experiments. 
cell progenitors results in only a mild defect in B cell development because of compensatory function of another ETS-family transcription factor, SPIB (Polli et al., 2005; Sokalski et al., 2011; Ye et al., 2005). PU.1 and SPIB associate with nearly identical regions of the genome in $B$ cells and regulate transcription of a similar cohort of genes (Solomon et al., 2015). Combined loss of PU.1 and SPIB impairs B cell maturation in the bone marrow and predisposes to the development of B cell leukemia (Sokalski et al., 2011).

We previously demonstrated that SPIC, an ETS-family transcriptional repressor with homology to PU.1 and SPIB, also functions in pre-B cells (Bednarski et al., 2016; Bemark et al., 1999; Hashimoto et al., 1999). Unlike PU.1 and SPIB, SPIC is not constitutively expressed in early $B$ cells but, rather, is induced by signals from RAG DSBs (Bednarski et al., 2016). SPIC operates primarily as a transcriptional repressor and counters the activating functions of PU.1 and SPIB (Li et al., 2015; Zhu et al., 2008). In pre-B cells, SPIC suppresses expression of Syk and $B / n k$, which inhibits pre-BCR signaling and enforces cell-cycle arrest in pre-B cells with RAG DSBs (Bednarski et al., 2016). SPIC also inhibits transcription of lgk to prevent generation of additional RAG DSBs (Bednarski et al., 2016). Binding of SPIC to gene-regulatory elements for Syk, BInk, and Igk is associated with loss of PU.1 at these genomic regions. Thus, expression of SPIC antagonizes PU.1 as these identified genes to suppress transcription and coordinate pre-B cell development.

Whether SPIC has broader functions in gene regulation and its mechanism of action in B cells have not been defined. SPIC may oppose PU.1 at limited gene targets or, alternatively, may modulate PU.1 activity throughout the genome. In this regard, attenuation of PU. 1 activity by SPIC could suppress pre-B cell genetic programs to promote continued B cell maturation. SPIC may function simply by displacing PU.1 through competition for DNA binding sites or may complex with other transcriptional regulators to repress transcription. We show here that, in response to RAG DSBs, SPIC binds throughout the genome of pre-B cells and elicits global changes in PU. 1 chromatin association. SPIC associates with the transcriptional repressor BCLAF1 (Bcl2associated factor 1) to regulate a distinct subset of RAG DSBdependent gene expression changes and to enforce transition from large to small pre-B cells. These experiments provide insight into the regulation of ETS transcription factors in early $B$ cells and the impact of DDR signaling on B cell development.

\section{RESULTS}

\section{RAG DSB Signals Induce Genome-Wide Changes in PU.1 Binding}

To determine the effects of DNA damage signaling on PU.1 activity in early $B$ cells, we used Abelson-kinase transformed pre-B cells (abl pre-B cells) deficient in RAG1 or the Artemis endonuclease that express the $B c / 2$ transgene $\left(\mathrm{Rag}^{-1-}: \mathrm{Bc} / 2\right.$ and $\mathrm{Art}^{-1-}: \mathrm{BCl} 2$, respectively) (Bredemeyer et al., 2008). Expression of the Abl kinase promotes pre-B cell proliferation and suppresses expression of Rag1 and Rag2. Treatment with the Abl kinase inhibitor imatinib triggers cell-cycle arrest, induction of RAG expression, and recombination of lgk (Bredemeyer et al., 2008). The Bc/2 transgene supports survival of imatinib-treated cells. Following treatment with imatinib, $R a g 1^{-1-}: B c / 2$ abl pre-B cells do not generate RAG DSBs. In contrast, $\mathrm{Art}^{-/-}: \mathrm{Bc} / 2$ abl pre-B cells generate RAG DSBs at lgk, but these DSBs are not repaired as Artemis is required to open hairpin-sealed coding DNA ends (Figure 1A) (Bredemeyer et al., 2008; Helmink and Sleckman, 2012). The RAG DSBs in $\mathrm{Art}^{-\prime-}: \mathrm{Bcl} 2$ abl pre-B cells activate ATM-dependent DDRs (Bednarski et al., 2012, 2016; Bredemeyer et al., 2008).

Chromatin immunoprecipitation followed by next-generation DNA sequencing (ChIP-seq) reveals global changes in PU.1 binding in pre-B cells with RAG DSBs $\left(\mathrm{Art}^{-1-}: \mathrm{Bc} / 2\right)$ compared with pre-B cells without RAG DSBs $\left(\operatorname{Rag} 1^{-1-}: B c / 2\right)$, despite no differences in PU.1 expression (Figures 1B, 1C, and S1A). Induction of RAG DSBs results in gain of few new binding sites but loss of approximately $20 \%$ of the PU. 1 binding sites identified in $\operatorname{Rag}^{-/-}:$Bcl2 abl pre-B cells (Figure 1B). Gene Ontology analysis demonstrates that genes within $12 \mathrm{~kb}$ of lost PU.1 binding sites are involved in immune cell activation and differentiation (Figure S1B). In contrast, PU.1 binding sites that are conserved between $\operatorname{Rag}^{-1-}: B c / 2$ and $A r t^{-/-}: B c / 2$ abl pre-B cells are proximal to genes involved in cell homeostasis and maintenance (i.e., signaling, nuclear transport, apoptosis). Novel RAG DSBinduced PU. 1 binding occurred near genes involved in cell adhesion and developmental processes. Induction of RAG DSBs did not alter PU. 1 binding across genomic regulatory elements as equal binding to promoters, genes, or intergenic regions (i.e., enhancers) is observed in both $\operatorname{Rag}^{-1-}: B c / 2$ and $A r t^{-1-}: B c / 2$ abl pre-B cells (Figure S1C). Thus, in response to RAG DSBs, pre-B cells have a genome-wide reduction in PU.1 chromatin binding, which is expected to result in changes in gene expression that affect important cellular functions.

Expression of SPIC Alters PU.1 Binding in Pre-B Cells RAG DSBs trigger ATM-dependent induction of SPIC (Figure 2A). Expression of SPIC, in turn, results in loss of PU. 1 binding at genes required for pre-BCR signaling (Bednarski et al., 2016). To determine if expression of SPIC is responsible for the global changes in PU.1 binding observed in response to RAG DSBs, we stably transduced $\operatorname{Rag}^{-1-}: B c / 2$ abl pre-B cells with a lentiviral vector encoding a tetracycline-inducible FLAG-HA-tagged SPIC (Rag $\left.1^{-1-}: B c / 2: S p i c^{\text {tet }}\right)$. Treatment with doxycycline induced equivalent SPIC mRNA expression as triggered by RAG DSBs (Figures 2A and 2B). We performed ChIP-seq for PU.1 in $\operatorname{Rag}^{-1-}: B c / 2: S p i C^{\text {tet }}$ abl pre-B cells treated with imatinib alone or in combination with doxycycline to induce expression of SPIC (Figure 2B). Expression of SPIC does not alter PU.1 expression

(B) Dot plot and heatmap of fold changes and signal intensity for PU.1 peaks identified by ChIP-seq in Rag $^{-1-}: B c / 2$ and $A r t^{-1-}: B c / 2$ abl pre-B cells treated with imatinib for $48 \mathrm{~h}$. Data are from common peaks identified in two replicates for each cell.

(C) Representative tracks at indicated regions for PU.1 ChIP-seq from (B). ChIP-qPCR validation for PU.1 binding at each locus is also shown. Data are mean and SE for three independent experiments. ${ }^{* *} \mathrm{p} \leq 0.01$ and ${ }^{\star \star \star \star} \mathrm{p} \leq 0.0001$; ns, not significant.

See also Figure S1. 
A

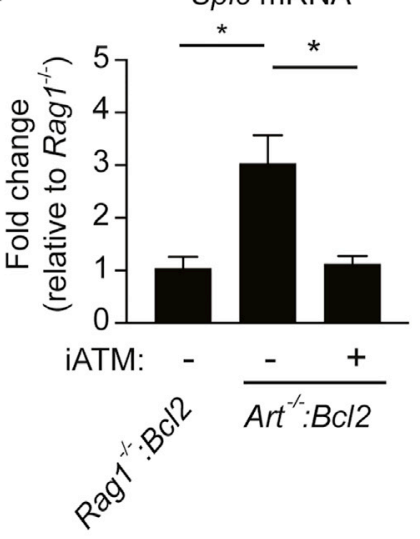

B

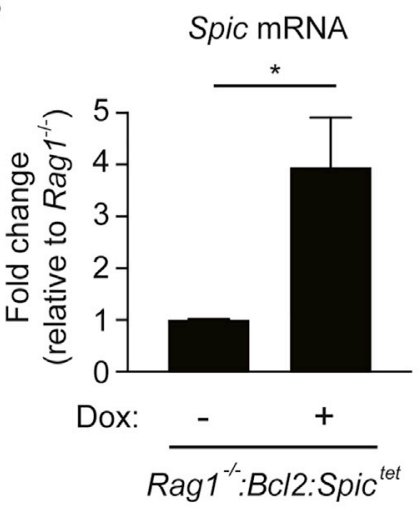

D

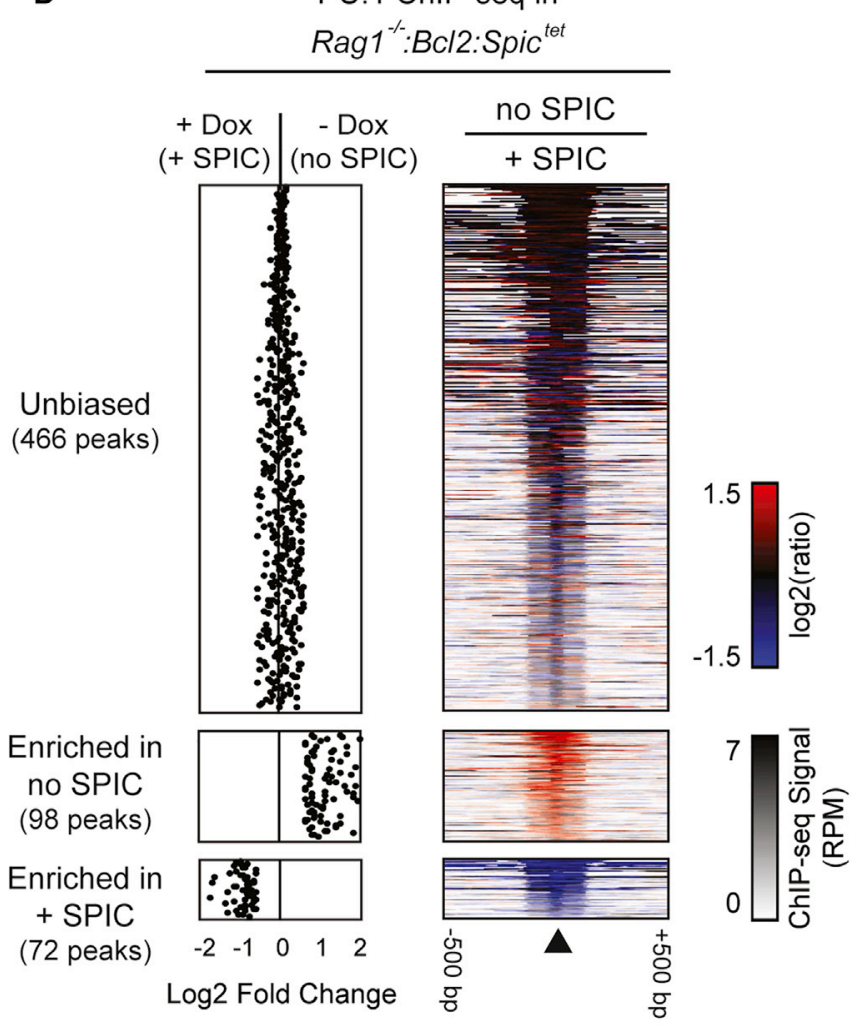

C

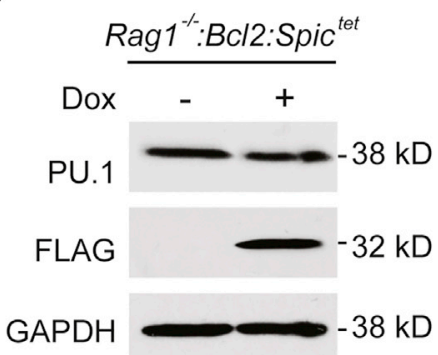

Figure 2. Expression of SPIC Alters PU.1 Binding

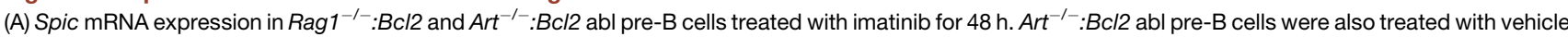
(-) or $15 \mu \mathrm{M}$ ATM inhibitor KU55933 (+ iATM). Data are relative to Rag $1^{-1-}: B c / 2$ and are mean and SE for three independent experiments.

(B) Spic mRNA expression in Rag $1^{-1-}: B c / 2: S p i c^{\text {tet }}$ abl pre-B cells treated with imatinib alone (-) or with imatinib and $2 \mu \mathrm{M}$ doxycycline (Dox; + ) for $48 \mathrm{~h}$. Data are relative to Rag $^{-1-}: B C / 2: S p i c^{\text {tet }}$ without doxycycline and are mean and SE for three independent experiments.

(C) Western blot shows PU.1 and SPIC (determined by anti-FLAG antibody) in Rag ${ }^{-1-}: B c / 2: S p i c^{\text {tet }}$ abl pre-B cells treated as in (B). Data are representative of three independent experiments.

(D) Dot plot and heatmap of fold changes and signal intensity for PU.1 peaks identified by ChIP-seq in Rag $1^{-1-}: B c l 2: S p i c^{\text {tet }}$ abl pre-B cells treated with imatinib alone (- Dox, no SPIC) or with imatinib and $2 \mu \mathrm{M}$ doxycycline (+ Dox, + SPIC) for $48 \mathrm{~h}$ as in (B). Data are from common peaks identified in two replicates for each cell line.

${ }^{*} \mathrm{p} \leq 0.05$.

but results in significant changes in PU.1 chromatin binding (Figures 2C and 2D). Moreover, expression of SPIC results in changes in PU.1 binding that are similar to changes induced by
RAG DSBs (compare Figures 1B and 2D). These findings demonstrate that changes in PU.1 binding in response to RAG DSBs are, in large part, due to RAG DSB-mediated induction of SPIC. 
SPIC and PU.1 Bind to Identical Genomic Regions SPIC and PU.1 have homologous DNA binding domains and have been previously shown in vitro to bind to the same DNA sequence (Bemark et al., 1999; Hashimoto et al., 1999). Current commercial antibodies against endogenous SPIC do not work for ChIP. Thus, to determine if SPIC and PU.1 binding to chromatin is similarly distributed throughout the genome, we performed ChIP-seq with anti-HA antibodies to precipitate FLAG-HA-SPIC in Rag $^{-1-}: B c / 2: S p i c^{\text {tet }}$ abl pre-B cells treated with doxycycline (to induce SPIC). Results were compared with findings from ChIP-seq for PU. 1 in $R a g 1^{-1-}: B c / 2$ abl pre-B cells without SPIC expression. Peaks with $\geq 1$ bp of overlap between the two ChIP-seq datasets were considered as enriched for binding to both transcription factors. We find that SPIC and PU.1 bind to similar locations throughout the genome (Figure 3A). Additionally, PU.1 binding is lost at sites where SPIC is bound (Figures 3B, 3C, and S2).

The ChIP peaks for SPIC and PU. 1 in regions where both transcription factors bind (common peaks in Figure $3 \mathrm{~A}$ ) have significant nucleotide overlap (Figures 3D). Indeed, the majority of these shared binding sites overlap by $>70 \%$, and the greatest number of ChIP peaks have $>90 \%$ overlap. Furthermore, SPIC and PU. 1 bind to similar regions throughout the genome (Figure 3E). Collectively, these findings demonstrate that SPIC and PU.1 bind to similar regulatory elements in pre-B cells and that SPIC binding results in displacement of PU. 1 from these regions.

\section{SPIC Recruits BCLAF1 to Chromatin}

PU.1 forms heterodimeric complexes with IRF4 or IRF8 to regulate transcription initiation (Brass et al., 1996; Heinz et al., 2010). SPIC does not complex with IRF4 or IRF8 but binds to similar DNA sequences as PU.1 (Carlsson et al., 2003). These findings raise the question of whether SPIC complexes with distinct protein partners to regulate gene expression. To identify SPIC interacting partners, we generated $\mathrm{Art}^{-1-}: \mathrm{Bc} / 2$ abl pre-B cells expressing either a tetracycline-inducible FLAG-HA-tagged SPIC $\left(\right.$ Art $^{-1-}: B c / 2:$ Spic $^{\text {tet }}$ ) or a tetracycline-inducible FLAG-HA-tagged PU.1 ( $\left.\mathrm{Art}^{-1-}: \mathrm{Bc} / 2: \mathrm{Pu}^{\text {tet }}\right)$. Cells were treated with imatinib to induce RAG DSBs and with doxycycline to induce comparable expression of the FLAG-tagged transcription factors (Figure S3). SPIC and PU.1 were immunoprecipitated using anti-FLAG antibodies, and associated proteins were identified by tandem mass spectrometry. Unique peptides were compared with identify proteins enriched for binding to SPIC (Figure 4A; Table S1). We focused on nuclear proteins with functions in transcriptional regulation. One of these proteins that enriched for binding to SPIC and not PU.1 is BCLAF1 (Figures $4 \mathrm{~A}$ and $4 \mathrm{~B}$ ). BCLAF1 was originally identified as a transcriptional repressor but has also been shown to promote gene expression in response to DNA damage (Kasof et al., 1999; Liu et al., 2007; Shao et al., 2016). Bclaf1-deficient mice have reduced T cells and increased splenic $B$ cell numbers, suggesting that BCLAF1 may function in immune development (McPherson et al., 2009).

Reciprocal co-immunoprecipitation experiments demonstrate that BCLAF1 selectively associates with SPIC and not PU.1 in $\mathrm{Art}^{-1-}: \mathrm{Bc} / 2 \mathrm{abl}$ pre-B cells (Figures $4 \mathrm{~B}$ and $4 \mathrm{C}$ ). In contrast, IRF4 and IRF8 associate with PU.1 but do not complex with SPIC (Figure 4B). To determine if BCLAF1 is recruited to
SPIC-bound chromatin in pre-B cells, we compared BCLAF1 ChIP-seq with SPIC ChIP-seq. A significant portion (>80\%) of BCLAF1 and SPIC peaks overlap indicating that the two proteins associate with similar chromatin regions (Figure 4D). Consistent with ChIP-seq results, BCLAF1 binding to the Syk promoter is increased in cells expressing SPIC (Figure 4E). Additionally, ChIP-re-ChIP experiments show that BCLAF1 only associates with the SPIC-bound Syk promoter and not with the PU.1-bound promoter (Figure 4F). Finally, BCLAF1 binding to the Syk promoter is increased in pre-B cells with RAG DSBs (Art $\left.{ }^{-\prime}: B c / 2\right)$, which express SPIC (Figures 4G and 2A). BCLAF1 ChIP peaks contain the conserved ETS DNA binding sequence (GGAA, $p<$ $1 \times \mathrm{e}^{-33}$ ) suggesting that it may not directly bind DNA but rather is recruited to chromatin by SPIC in response to RAG DSBs in pre-B cells.

\section{SPIC and BCLAF1 Regulate Gene Expression in Pre-B Cells}

We previously showed that in response to RAG DSBs, SPIC represses expression of key genes required for pre-BCR signaling (Bednarski et al., 2016). Given our current findings that SPIC and its partner BCLAF1 bind throughout the genome, we hypothesized that this complex regulates a broad genetic program in pre-B cells. To identify the genes regulated by SPIC, we compared transcriptional changes in $\operatorname{Rag}^{-1-}: B \mathrm{BCl} 2:$ Spic ${ }^{\text {tet }}$ abl pre-B cells with and without expression of SPIC. Expression of 866 genes was changed $\geq 2$-fold (adjusted $p<0.05$ ) following expression of SPIC (Figures 5A and S4A; Table S2). Knockdown of BCLAF1 in SPIC-expressing Rag $1^{-1-}: B c / 2: S p i C^{\text {tet }}$ abl pre-B cells changes expression of $55 \%$ of SPIC-regulated genes ( $\geq 2$-fold change, adjusted $p<0.05$ ) (Figures 5B, 5C, and S4A; Table S2). Notably, genes repressed by SPIC were rescued following knockdown of BCLAF1 (Figures 5C and S4A). Gene Ontology analysis revealed that SPIC- and BCLAF1-dependent genes are enriched for immune processes in B cells (Figure S4B). Importantly, loss of BCLAF1 does not alter SPIC binding to the Syk promoter, suggesting that recruitment of BCLAF1 is needed for SPIC-mediated transcriptional changes but not for SPIC binding to chromatin (Figure 5D).

We then determined the contribution of SPIC/BCLAF to the genetic program regulated by RAG DSBs in pre-B cells. Gene profiling revealed that $B C L A F 1$ regulates a significant portion of RAG DSB-mediated genes (540 of 717 genes, $\geq 2$-fold change, adjusted $p<0.05$; Figure 5E; Table S3). Comparison of RAG DSB-dependent (Art ${ }^{-/-}: B c / 2$ versus Rag $1^{-1-}: B c / 2$; Figure 5E), SPIC-dependent (Rag $1^{-1}: B c / 2: S p i c^{\text {tet }}$ expressing SPIC versus $\operatorname{Rag}^{-1-}: B c / 2$; Figure $\left.5 \mathrm{~A}\right)$, and BCLAF1-dependent $\left(\right.$ Art $^{-1-}: B c / 2$ expressing shBCLAF1 versus $\mathrm{Art}^{-1-}: \mathrm{BCl} 2$; Figure $5 \mathrm{E}$ ) gene expression changes identified 141 genes whose expression is modulated by all three variables (Figures $5 \mathrm{~F}, 5 \mathrm{G}$, and S5A; Table S4). Approximately $25 \%$ of these genes have concordant changes in expression (repressed by RAG DSBs, repressed by SPIC, and rescued by loss of BCLAF1; Figure S5A). Pathway analyses are enriched for diverse B cell functions, including proliferation, cell adhesion, and cell death (Figure S5B). These findings demonstrate that the SPIC/BCLAF1 complex regulates a distinct genetic program in pre-B cells with RAG DSBs. 
A

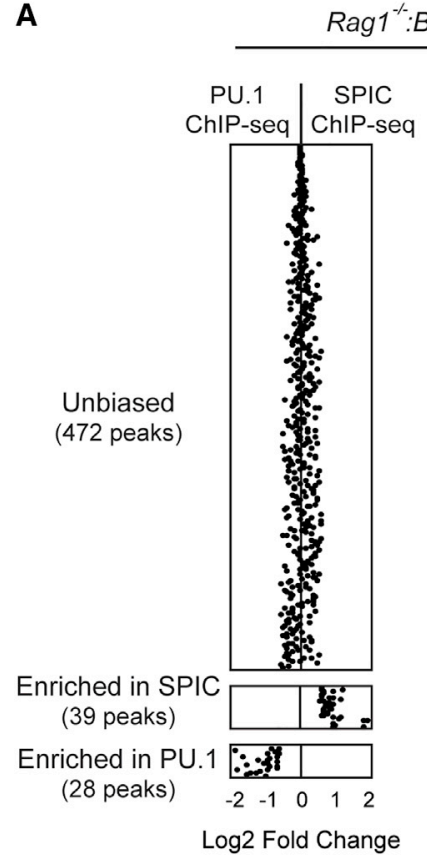

C

PU.1 ChIP
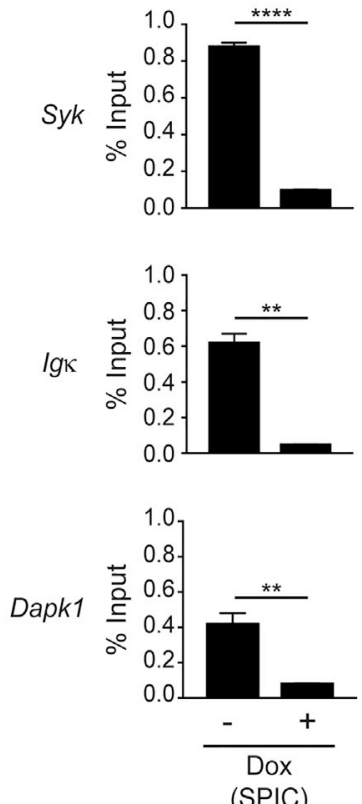

SPIC ChIP
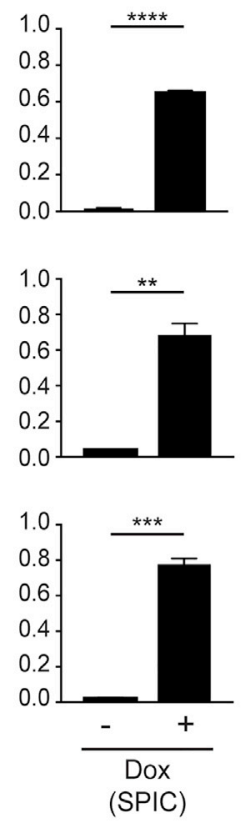

B
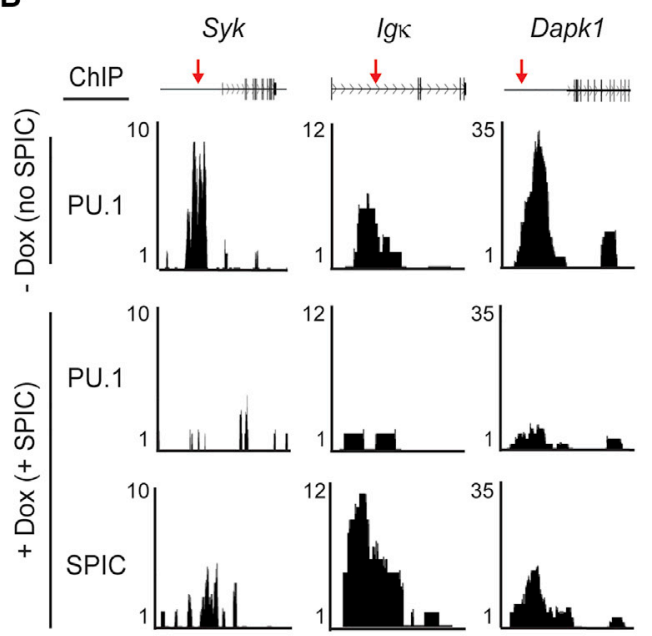

D

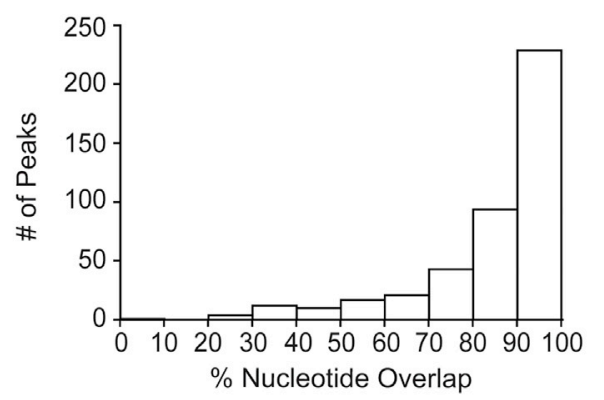

E

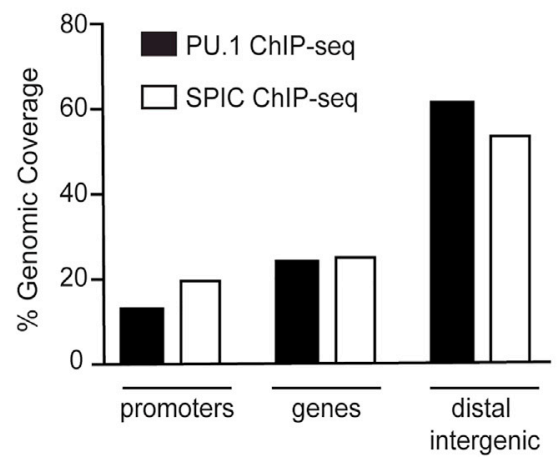

Figure 3. SPIC and PU.1 Bind to Identical Genomic Regions

(A) Dot plot and heatmap of fold changes and signal intensity for PU.1 and SPIC (by anti-HA ChIP) peaks identified by ChIP-seq in Rag ${ }^{-/-}$:Bc/2:Spic ${ }^{\text {tet }}$ abl pre-B cells treated with imatinib for $48 \mathrm{~h}$ in the absence (for PU. $1 \mathrm{ChIP}$ ) or presence (for SPIC ChIP) of $2 \mu \mathrm{M}$ doxycycline (Dox). Data are from common peaks identified in two replicates of each cell line.

(B) Representative ChIP-seq binding of PU.1 and SPIC at indicated regions. PU.1 ChIP-seq was performed in Rag $1^{-1-}: B c / 2: S p i c^{\text {tet }}$ abl pre-B cells treated with imatinib alone (- Dox, no SPIC) or with imatinib and doxycycline to induce expression of SPIC (+ Dox, + SPIC) for $48 \mathrm{~h}$. ChIP-seq for SPIC was performed as in A in $\operatorname{Rag}^{-1-}: B c / 2: S p i c^{\text {tet }}$ abl pre-B cells treated with imatinib and doxycycline for $48 \mathrm{~h}$. 
A

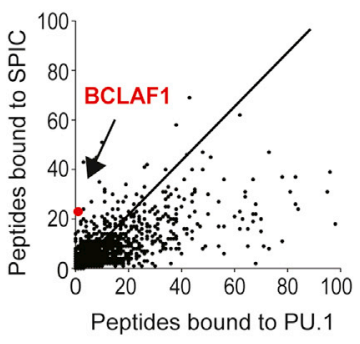

C

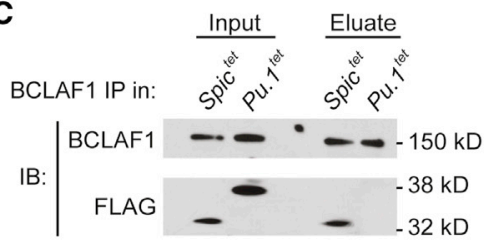

D

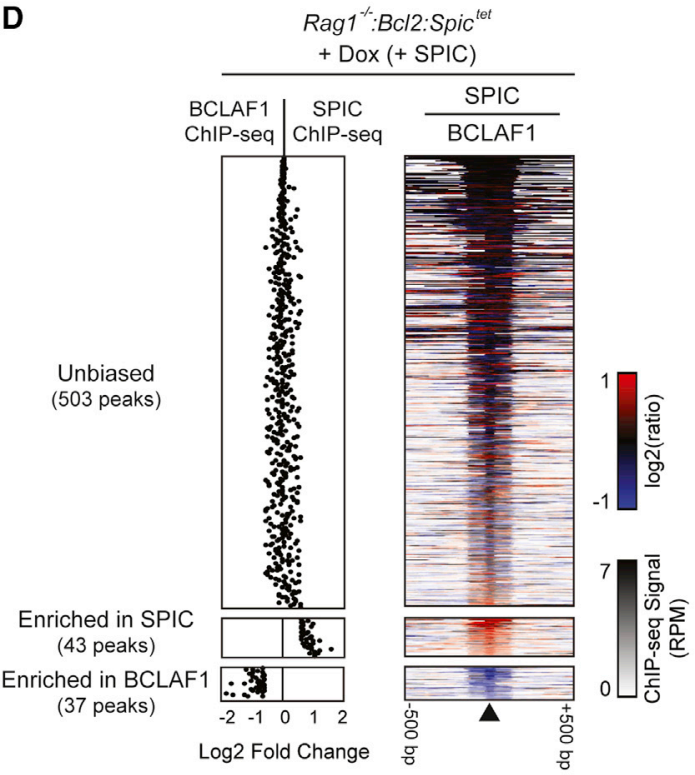

B

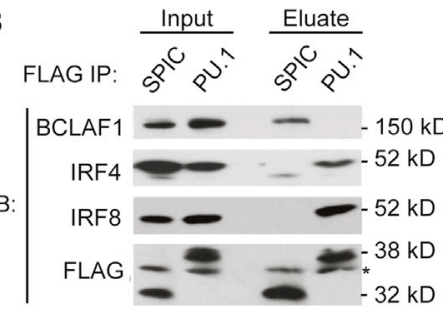

E

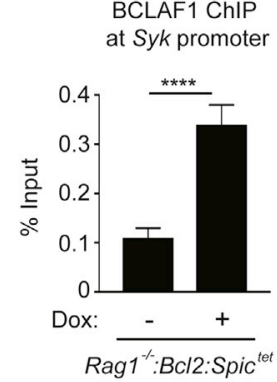

$\mathbf{F}$

ChIP re-ChIP for BCLAF1 at Syk promoter

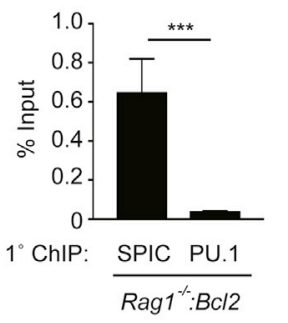

G

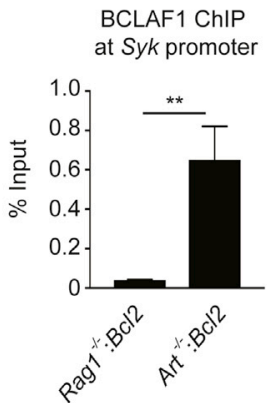

Figure 4. SPIC Recruits BCLAF1 to Chromatin

(A) FLAG-HA-SPIC and FLAG-HA-PU.1 were immunoprecipitated from $\mathrm{Art}^{-1-}: \mathrm{BCl} / \mathrm{Spic}^{\text {tet }}$ and Art ${ }^{-1-}: B c / 2: P u .1^{\text {tet }}$, respectively, after treatment with imatinib and $2 \mu \mathrm{M}$ doxycycline for $48 \mathrm{~h}$. Scatterplot shows number of total peptides per protein identified by mass spectrometry analysis of co-immunoprecipitation of SPIC (y axis) versus PU.1 (x axis).

(B) FLAG-HA-tagged SPIC and FLAG-HA-tagged PU.1 were immunoprecipitated from $\mathrm{Art}^{-1-}: \mathrm{BCl} 2$ : Spic tet and Art $^{-1-}: B c / 2: P u .1^{\text {tet }}$ abl pre-B cells, respectively, treated as in (A). IP samples were immunoblotted (IB) for BCLAF1, IRF4, IRF8, and FLAG. Asterisk indicates non-specific band.

(C) BCLAF1 was immunoprecipitated from Art $^{-1-}: B c / 2:$ Spic $^{\text {tet }}\left(\right.$ Spic $\left.^{\text {tet }}\right)$ and Art $^{-1-}: B c / 2: P u .1^{\text {tet }}$ $\left(P u .1^{\text {tet }}\right)$ abl pre-B cells treated as in (A). IP samples were immunoblotted for BCLAF1 and FLAG.

(D) Dot plot and heatmap of fold changes and signal intensity for BCLAF1 and SPIC peaks (by anti-HA ChIP as in Figure $3 A$ ) identified by ChIPseq in $R a g 1^{-1-}: B c / 2: S p i c^{\text {tet }}$ abl pre-B cells treated with imatinib and $2 \mu \mathrm{M}$ doxycycline for $48 \mathrm{~h}$. Data are from common peaks identified in two replicates of each cell line.

(E) ChIP-qPCR of BCLAF1 binding at the Syk promoter in Rag $^{-1-}: B c / 2: S p i c^{\text {tet }}$ abl pre-B cells treated with imatinib for $48 \mathrm{~h}$ in the absence $(-)$ or presence (+) of $2 \mu \mathrm{M}$ doxycycline (Dox) to induce SPIC expression.

(F) Re-ChIP for BCLAF1 after primary ChIP for SPIC or PU.1 (using anti-HA antibodies) in Rag1 $^{-1-}:$ Bcl2:Spic ${ }^{\text {tet }}$ or Rag $1^{-1-}: B c / 2: P u .1^{\text {tet }}$ abl pre-B cells, respectively, treated with imatinib and $2 \mu \mathrm{M}$ doxycycline for $48 \mathrm{~h}$.

(G) ChIP-qPCR of BCLAF1 binding at the Syk promoter in $\operatorname{Rag}^{-1-}: \mathrm{Bc} / 2$ and $\mathrm{Art}^{-1-}: \mathrm{Bcl} 2 \mathrm{abl}$ pre-B cells treated with imatinib for $48 \mathrm{~h}$.

Data in $(A-C)$ are representative of three independent experiments. Data in $(E-G)$ are mean and $S E$ for three independent experiments. ${ }^{* *} \mathrm{p} \leq 0.01$ ${ }^{* * *} p \leq 0.001$, and ${ }^{* \star *} p \leq 0.0001$

See also Figure S3 and Table S1.

\section{BCLAF1 Regulates Pre-BCR Signaling in Primary Pre-B Cells}

To determine if BCLAF1 is required for regulation of SPIC function in primary pre-B cells, we expanded pre-B cells from $\operatorname{Rag}^{-1^{-}}: \mu \mathrm{lgh}: \mathrm{Bcl} 2$ and $A \mathrm{rt}^{-{ }^{-}}: \mu \mathrm{lgh}: \mathrm{Bcl} 2$ mice in the presence of interleukin-7 (IL-7) (Bednarski et al., 2012, 2016). The $\mu$ lgh transgene permits expression of a pre-BCR, which promotes transition to the pre-B cell developmental stage (Bed- narski et al., 2012, 2016). IL-7 promotes proliferation and expansion of large pre-B cells. Withdrawal of IL-7 induces cell-cycle arrest, transition to small pre-B cells, expression of RAG, and induction of RAG DSBs at Igk (Bednarski et al., 2012, 2016; Johnson et al., 2008; Ochiai et al., 2012; Rolink et al., 1991; Steinel et al., 2013). Consistent with our previous findings, withdrawal of IL-7 results in induction of SPIC and suppression of Syk transcripts in pre-B cells with RAG DSBs

(C) ChIP-qPCR validation for PU.1 and SPIC binding at each locus shown in (B). Data are mean and SE for three independent experiments. ${ }^{\star \star} \mathrm{p} \leq 0.01,{ }^{\star \star \star} \mathrm{p} \leq$ 0.001 , and ${ }^{\star * \star *} p \leq 0.0001$.

(D) Nucleotide overlap between PU.1 and SPIC peaks identified in (A). Peaks were grouped in bins on the basis of percentage of overlap as shown.

(E) Enrichment of PU.1 and SPIC binding across genomic regions on the basis of ChIP-seq data in (A).

See also Figure S2. 
A Gene expression changes in $\operatorname{Rag}^{-\kappa}: \mathrm{BCl} 2:$ Spic ${ }^{\text {tet }}$ following induction of Spic

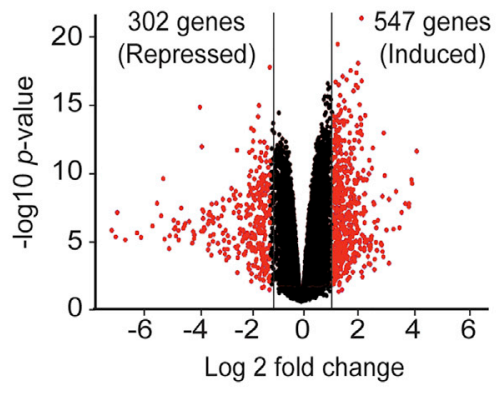

B

$$
\operatorname{Rag}^{-1}: \mathrm{Bcl} 2: \text { Spic }^{\text {tet }}
$$

(+ Dox, + SPIC)

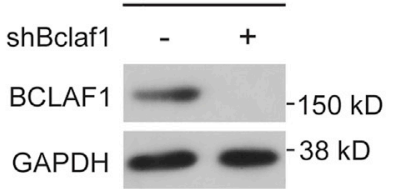

C
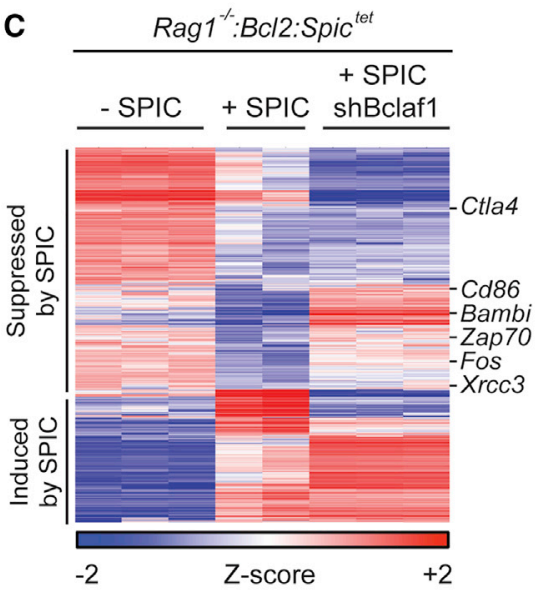

D

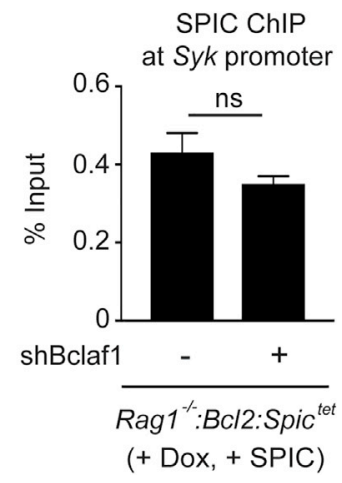

E

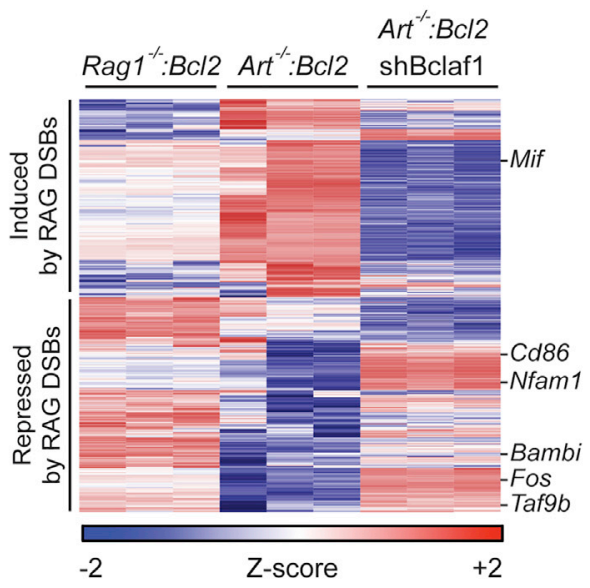

$\mathbf{F}$

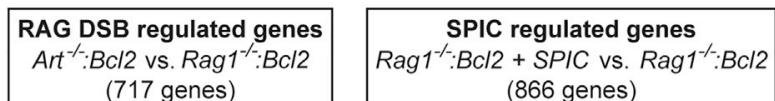
(717 genes) (866 genes)

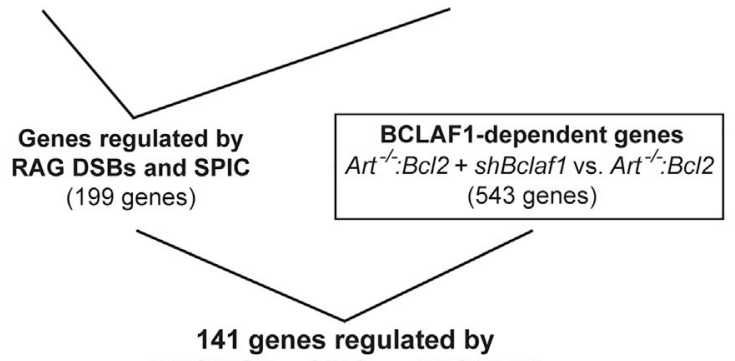

RAG DSBs, SPIC and BCLAF1

G
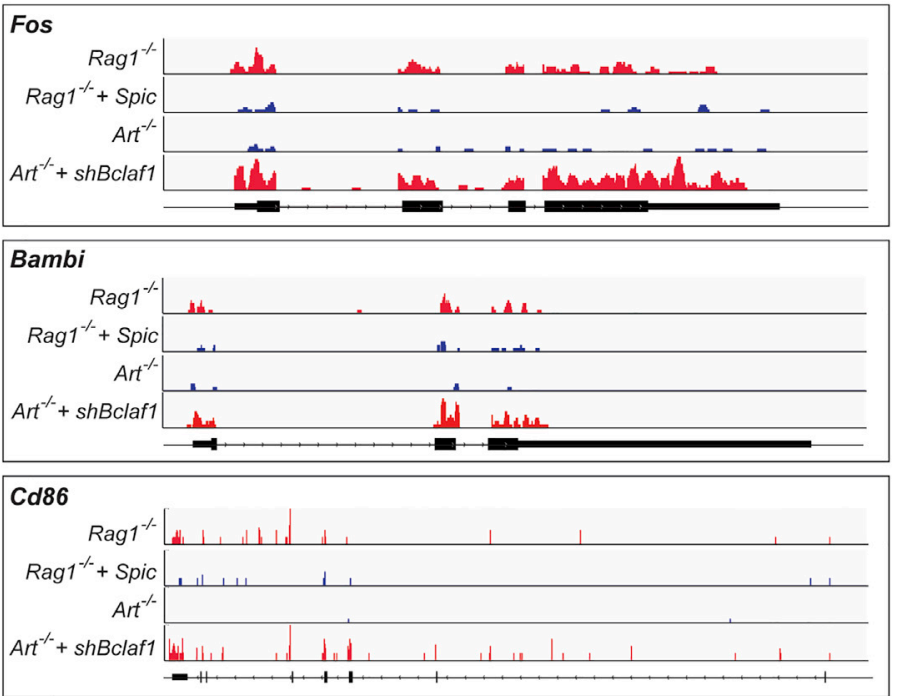

Figure 5. SPIC and BCLAF1 Regulate Gene Expression in Pre-B Cells in Response to RAG DSBs

(A) Volcano plot of gene expression changes (fold change $\geq 2, p \leq 0.05$ ) between Rag $1^{-1-}: B c / 2$ :Spic ${ }^{\text {tet }}$ abl pre-B cells with and without SPIC induction. RNA-seq was performed on $\operatorname{Rag}^{-1-}: B c / 2: S p i c^{\text {tet }}$ abl pre-B cells treated with imatinib alone (-SPIC) or with imatinib and $2 \mu \mathrm{M}$ doxycycline $(+\mathrm{SPIC})$ for $48 \mathrm{~h}$. Data are from two independent cultures for each treatment. 
(Art $\left.{ }^{-1-}: \mu l g h: B c / 2\right)$ (Figures 6A and 6B) (Bednarski et al., 2016). Loss of BCLAF1 does not alter induction of Spic but does lead to increased expression of Syk in $\mathrm{Art}^{-1-}: \mu \mathrm{lgh}: B c / 2$ small pre-B cells (Figures $6 \mathrm{~A}$ and $6 \mathrm{~B}$ ). Consistent with the rescue of Syk mRNA levels, SYK protein is increased in $\mathrm{Art}^{-1-}:$ Igh:Bcl2 pre-B cells lacking BCLAF1 to levels equivalent to those

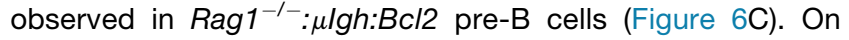
the basis of these results, we conclude that BCLAF1 is necessary for repression of SYK in response to RAG DSBs in primary small pre-B cells.

To assess BCLAF1 binding to the Syk promoter during wildtype pre-B cell development in vivo, we used Spicigfpligfp mice, which contain an IRES-EGFP targeted to the $3^{\prime}$ non-coding exon of Spic (Haldar et al., 2014). Approximately $2 \%$ of small pre-B cells from Spicigfoligfp mice are EGFP positive, indicative of SPIC expression (Figures 6D and 6E). EGFP-expressing small pre-B cells are not observed in $\mathrm{Atm}^{-1-}:$ Spic ${ }^{\text {igfoligfp }}$, indicating that induction of SPIC (and EGFP) depends on DNA damage signaling (Figure 6E). SPIC-expressing Spic igfo/igfp small pre-B cells (EGFP positive) have reduced PU. 1 binding and increased BCLAF1 binding to the Syk promoter as well as decreased Syk expression (Figures 6F-6H) (Bednarski et al., 2016). These results suggest that SPIC/BCLAF1 complex is induced by DNA damage signals from transient RAG DSBs generated during $|g|$ rearrangement in wild-type small pre-B cells.

\section{Loss of BCLAF1 Alters Large to Small Pre-B Cell Transition}

Activation of SYK downstream of the pre-BCR can promote pre-B cell proliferation in the absence of IL-7 signaling (Clark et al., 2014; Herzog et al., 2009; Ochiai et al., 2012; Rolink et al., 2000; Wossning et al., 2006). Given that loss of BCLAF1 prevents SPIC-mediated repression of SYK, we hypothesized that loss of BCLAF1 may alter pre-B cell proliferation and the transition from large to small pre-B cells during early $B$ cell develop-

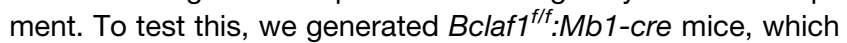
have selective loss of BCLAF1 in B cells (Figure 7A) (Hobeika et al., 2006). Pre-B cells from Bclaf1 ${ }^{f / f}: M b 1-c r e$ and Bclaf1 ${ }^{f / f}$ mice were expanded in the presence of IL-7. Following IL-7 with-

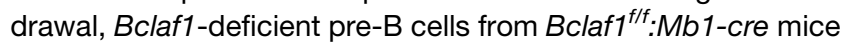
have increased S-phase progression and increased Syk expression compared with pre-B cells from Bclaf1 ${ }^{\mathrm{f} / \mathrm{f}}$ and $\mathrm{Mb} 1$-cre mice (Figures 7B-7D). These findings support a role for BCLAF1 in the regulation of pre-B cell proliferation possibly through modulation of SYK activity downstream of pre-BCR signaling.
We next assessed B cell populations in vivo. In our breeding, Mb1-cre mice have normal numbers of pro-B cells but reduced pre-B cells relative to littermate wild-type $\mathrm{Bclaf1}^{\mathrm{f} / \mathrm{f}}$ mice (Figures 7E and S6). In contrast, Bclaf1 ${ }^{f / f}: M b 1$-cre mice have increased numbers of pre-B cells compared with Mb1-cre mice and are similar to Bclaf1 ${ }^{f / f}$ mice (Figure $7 \mathrm{E}$ ). Interestingly, the increase

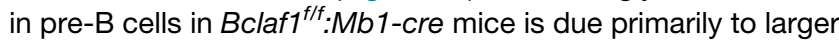
numbers of large pre-B cells (Figure 7E). Loss of Bclaf1 does not alter numbers of pro-B cells or small pre-B cells. Consistent with findings in cultured cells, in vivo large, proliferating pre-B cells from Bclaf1 ${ }^{f / f}: M b 1-c r e$ mice have increased Syk mRNA levels (Figure 7F). Syk expression is not altered in small pre-B cells (Figure 7F). We propose that BCLAF1 functions in response to RAG DSBs in pre-B cells to suppress Syk and enforce transition from the large to small pre-B cell developmental stage.

\section{DISCUSSION}

Here we show that RAG DSBs induce genome-wide changes in PU.1 localization and function, which coordinates a distinct genetic program in B cells undergoing lg gene rearrangement. This modulation of PU. 1 activity is mediated by RAG DSB activation of a SPIC/BCLAF1 transcriptional repressor complex. SPIC displaces PU.1 at gene regulatory sites but requires association with BCLAF1 to suppress transcription. This antagonistic function of SPIC/BCLAF1 coordinates a broad genetic program and enforces transition from large to small pre-B cells in response to RAG DSBs.

$\mathrm{PU} .1$ is a key regulator of cell fate decisions during early hematopoiesis and is essential for generating $B$ cells from hematopoietic progenitors (Dakic et al., 2007; DeKoter et al., 2002; Pang et al., 2018; Scott et al., 1994, 1997). PU.1 expression is high in myeloid cells, in which it is required to promote lineage specific gene expression (Heinz et al., 2010). In contrast, PU.1 expression is reduced during $B$ cell differentiation and remains low in established B cells (Back et al., 2005; Nutt et al., 2005). This differential activity of PU. 1 is critical for directing appropriate lineage commitment. Dysregulation of PU.1 expression leads to aberrant differentiation and can result in leukemic transformation (Anderson et al., 2002; Pang et al., 2016; Rosenbauer et al., 2004, 2006; Sokalski et al., 2011). PU.1 activity is also regulated through interaction with other transcription factors, which modulate its DNA binding properties or its transcriptional function (Maitra and Atchison, 2000; Nerlov et al., 2000; Rogers et al., 2016). For example, in early lymphoid precursors, E2A

(B) Western blot of BCLAF1 in Rag1 $1^{-1-}: B c / 2: S p i c^{\text {tet }}$ abl pre-B cells transduced with a retrovirus expressing a scrambled short hairpin RNA (shRNA) (-) or shBclaf1 $(+)$ and then treated with imatinib and $2 \mu \mathrm{M}$ doxycycline for $48 \mathrm{~h}$ (to induce SPIC). Data are representative of three independent experiments.

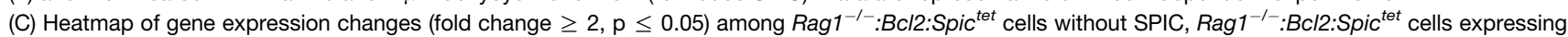
SPIC, and Rag1 ${ }^{-\prime-}: B c / 2: S p i c^{\text {tet }}$ cells expressing SPIC and shBclaf1. Cells were treated as in (A) and (B). Columns represent independent cultures for each cell line and treatment as indicated. Representative gene are delineated to the right.

(D) ChIP-qPCR of SPIC binding at the Syk promoter in Rag1 ${ }^{-1-}: B c / 2: S p i c^{\text {tet }}$ cells expressing a scrambled shRNA (-) or shBclaf1 (+) and treated as in (B). Data are mean and $\mathrm{SE}$ for three independent experiments. ns, not significant.

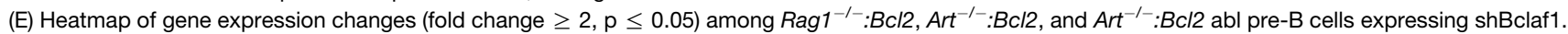
$A r t^{-\prime-}: B c / 2$ abl pre-B cells were transduced with a retrovirus expressing shBclaf1. RNA sequencing (RNA-seq) was performed on all cells after treatment with imatinib for $48 \mathrm{~h}$. Columns represent independent cultures for each cell line as indicated. Representative genes are delineated to the right. (F) Flow diagram showing identification of genes regulated by RAG DSBs, SPIC, and BCLAF1 in pre-B cells.

(G) Representative tracks at genes identified in F from RNA-seq in (C) and (E).

See also Figures S4 and S5 and Tables S2, S3, and S4. 
A

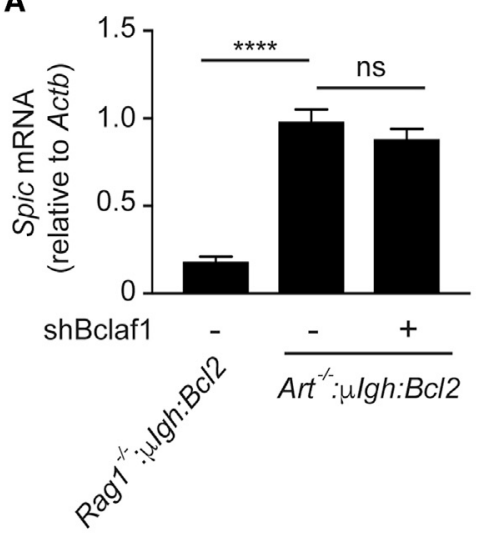

B

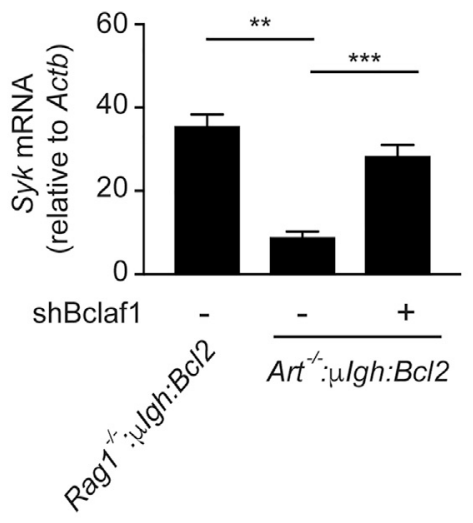

c

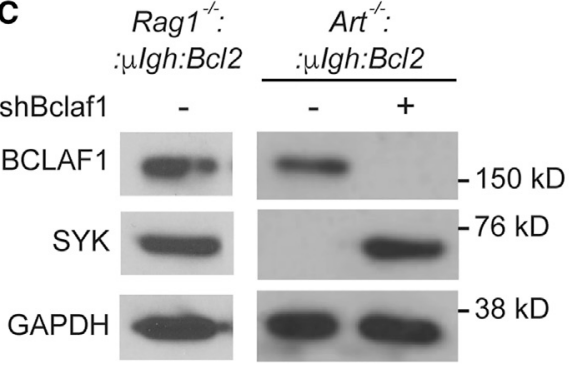

D

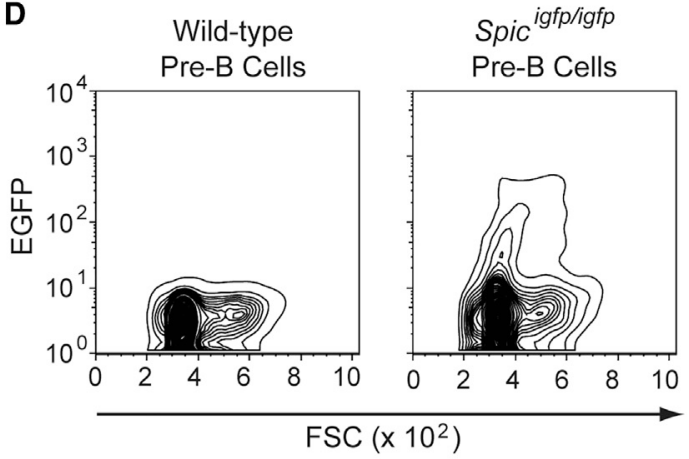

E

Small Pre-B Cells

F Small Pre-B Cells
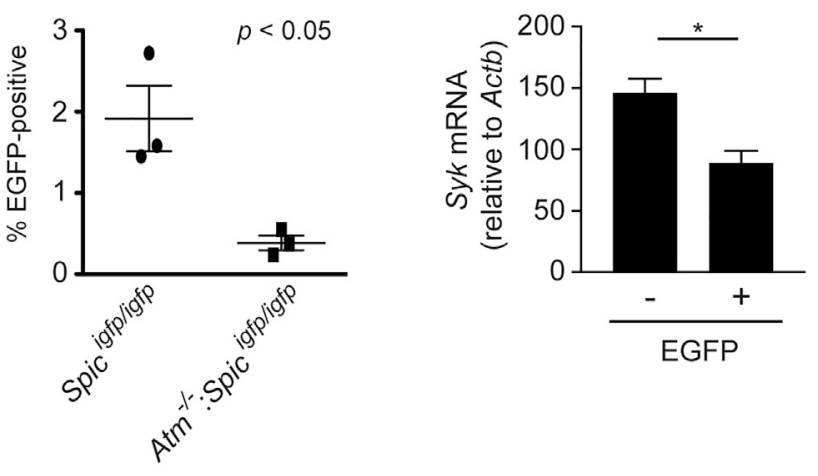

G

PU.1 ChIP at Syk promoter

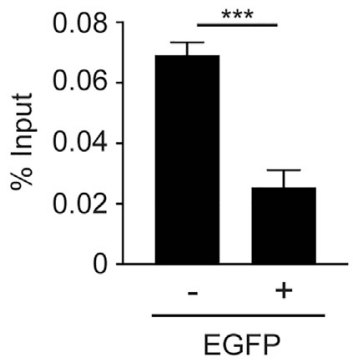

H BCLAF1 ChIP at Syk promoter

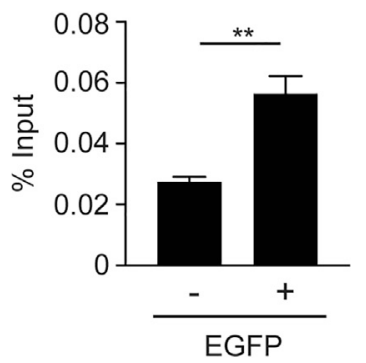

Figure 6. BCLAF1 Regulates SYK Expression in Primary Pre-B Cells

(A-C) Art $^{-1-}: \mu l g h: B c / 2$ pre-B cells were transduced with a retrovirus expressing a scrambled shRNA (-) or shBclaf1 (+) and then subsequently withdrawn from IL-7.

(A and B) Spic and Syk mRNA expression assessed in indicated small pre-B cells 2 days after IL-7 withdrawal. Data are mean and SE for three independent experiments.

(C) Western blot of SYK and BCLAF1 in indicated small pre-B cells 2 days after IL-7 withdrawal. Data are representative of three independent experiments. (D) Flow cytometric analysis showing EGFP ( $\mathrm{y}$ axis) and FSC (x axis) in bone marrow pre-B cells $\left(\mathrm{B}_{2} 20^{\text {lo }} \mathrm{CD}^{-} 3^{-} \mathrm{IgM}^{-}\right)$from wild-type and Spic ${ }^{\text {igfp/igfp }}$ mice. Data are representative of five independent experiments.

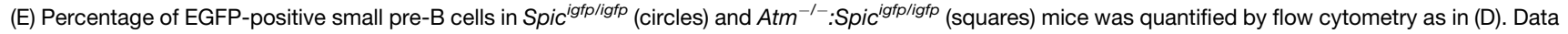
are mean and $\mathrm{SE}$ from three independent mice of each genotype.

(F-H) Syk mRNA expression (F), ChIP-PCR of PU.1 at Syk promoter (G), and ChIP-PCR of BCLAF1 at Syk promoter (H) in EGFP-negative (-) and EGFP-expressing $(+)$ small pre-B cells sorted from Spicigfpligfp mice. Data in $(F)$ are the mean and SE from three independent experiments. Data in $(G)$ and $(H)$ are representative of two independent experiments.

${ }^{\star} \mathrm{p} \leq 0.05,{ }^{\star \star} \mathrm{p} \leq 0.01,{ }^{\star \star \star} \mathrm{p} \leq 0.001,{ }^{\star \star \star \star} \mathrm{p} \leq 0.0001 ;$ ns, not significant. 
A

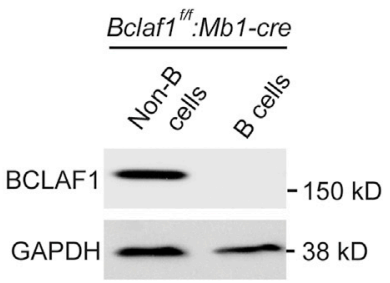

B

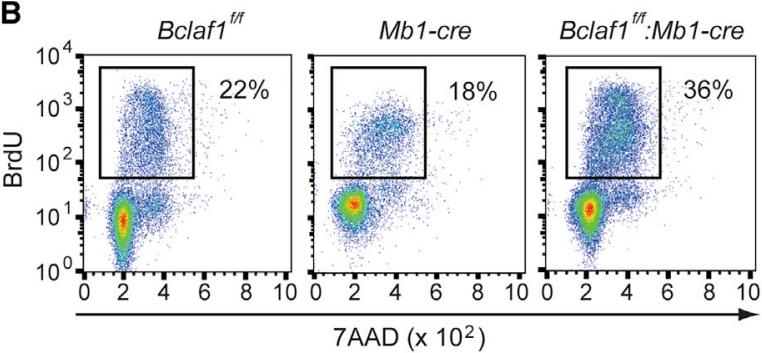

C

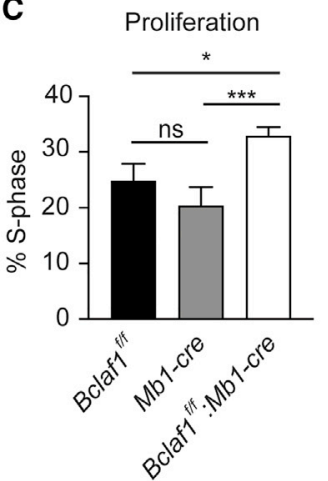

D

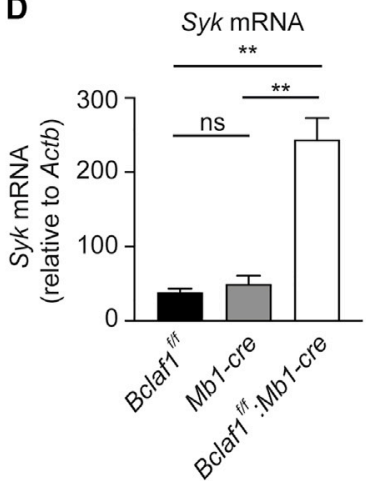

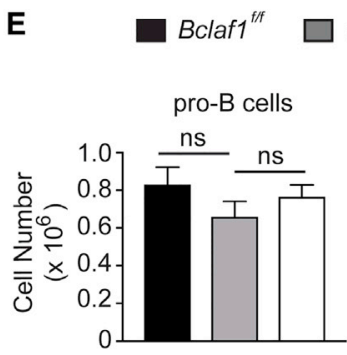

Small pre-B cells

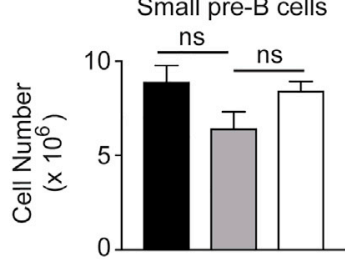

Syk mRNA in

$\mathbf{F}$

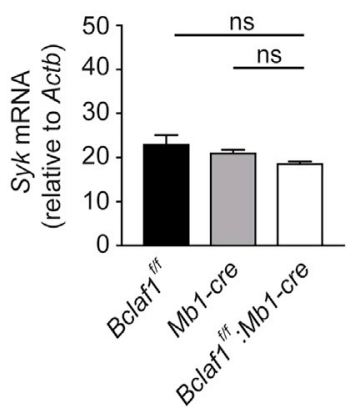

Mb1-cre $\square$ Bclaf1 ${ }^{\text {fff }}$ :Mb1-cre

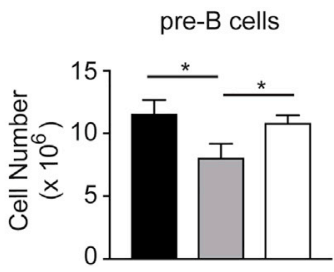

Large pre-B cells

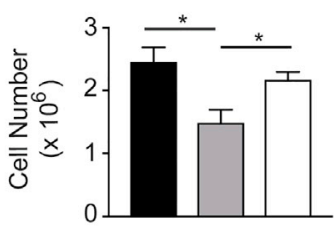

Syk mRNA in large pre-B cells

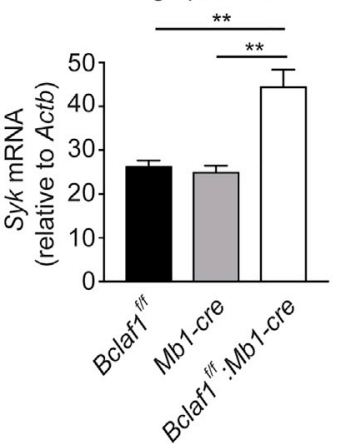

Figure 7. BCLAF1 Regulates Large to Small Pre-B Cell Transition

(A) Western blot of BCLAF1 in sorted CD19- (non-B cell) and CD19+ B cell populations from bone marrow of 5-week-old Bclaf1 ${ }^{f f f}:$ Mb1-cre mice. Data are representative of three independent mice.

(B) Flow cytometric analysis of BrdU incorporation (y axis) and DNA content (7AAD, $x$ axis) performed $24 \mathrm{~h}$ after IL-7 withdrawal. Percentage of cells that entered S phase during BrdU labeling (box) is indicated. Data are representative of at least three independent experiments.

(C) Percentage of cells that entered $\mathrm{S}$ phase in cell cycle analysis performed in (B). Data are mean and SE for four independent experiments.

(D) Syk mRNA expression $24 \mathrm{~h}$ after IL-7 withdrawal. Data are mean and SE for three independent experiments.

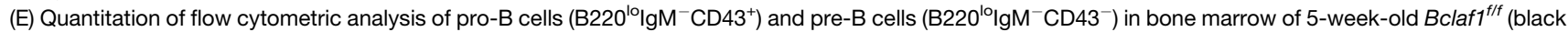
bars, $n=12$ ), Mb1-cre (gray bars, $n=9$ ), and Bclaf1 ${ }^{f / f}: M b 1$-cre (white bars, $n=12$ ) mice. Large and small pre-B cells were gated on the basis of forward-scatter and side-scatter characteristics.

(F) Syk mRNA expression in small and large pre-B cells sorted from 5-week-old Bclaf1 $1^{f / f}$ (black bars, $\left.n=4\right), M b 1$-cre (gray bars, $\left.n=5\right)$, and Bclaf1 ${ }^{f / f}: M b 1$-cre $($ white bars, $\mathrm{n}=5)$ mice.

Data in $(E)$ and $(F)$ are mean and SE for indicated numbers of mice. ${ }^{*} p \leq 0.05,{ }^{* *} p \leq 0.01$, and ${ }^{* * *} p \leq 0.001$; ns, not significant.

See also Figure S6.

association with PU.1 inhibits PU.1-induced transcription of myeloid genes and promotes $\mathrm{B}$ lymphoid differentiation (Rogers et al., 2016). We find that PU.1 activity is regulated at the pre-B cell developmental stage through RAG DSB-mediated induction of SPIC, which binds chromatin and displaces PU.1. This transcription factor exchange results in changes in expression of genes involved in pre-BCR signaling, B cell proliferation, and B cell differentiation.

SPIC and PU.1 have homologous DNA binding domains (Bemark et al., 1999; Hashimoto et al., 1999). As such, SPIC can compete for DNA binding sites occupied by PU.1, and binding of SPIC results in displacement of PU.1 from these sites. Interestingly, SPIC associates with $>90 \%$ of the PU. 1 sites, but PU. 1 binding is lost at only approximately $20 \%$ of the regions it binds in the absence of SPIC expression (Figures $2 \mathrm{D}$ and $3 \mathrm{~A}$ ). It is conceivable, then, that SPIC and PU.1 may simultaneously bind specific regions of the genome, and SPIC binding may not always fully displace PU.1. Rather, binding of SPIC nearby PU. 1 may alter PU.1 transcriptional activity or other transcriptional machinery at these sites. Alternatively, in an individual cell, each ETS site may be occupied by either SPIC or PU.1, but ChIP analysis on a bulk population is not 
sensitive enough to discriminate between these two different states.

In early B cells, PU.1 and SPIB are constitutively expressed and have complementary functions (Schweitzer and DeKoter, 2004; Scott et al., 1994, 1997; Sokalski et al., 2011; Solomon et al., 2015). As such, conditional deletion of either PU.1 or SPIB alone mildly alters B cell development, but loss of both transcription factors results in a block in B cell differentiation at the pro-B cell stage (Polli et al., 2005; Sokalski et al., 2011; Su et al., 1997; Ye et al., 2005). PU.1 and SPIB bind to similar regions throughout the genome of pro- $B$ cells and regulate expression of key developmental genes, including Syk and $B / n k$, which are necessary for pre-BCR signaling and induction of proliferation of large pre-B cells (Solomon et al., 2015). We find that SPIC also binds to the same genomic sites as PU.1. Given that SPIB and PU.1 bind identical regions and have complementary functions in early B cells, SPIC is also expected to counter SPIB similar to our observed results for PU.1. In contrast to PU.1 and SPIB, SPIC is inducibly expressed in pre-B cells in response to RAG DSBs and functions primarily as a transcriptional repressor. Expression of SPIC opposes PU.1 and SPIB activity resulting in suppression of pre-BCR and BCR signaling in early B cells and mature B cells, respectively, leading to a block in B cell maturation or function (Bednarski et al., 2016; Zhu et al., 2008). Importantly, complete or permanent inhibition of PU.1 and SPIB could be detrimental to $\mathrm{B}$ cell development, as combined loss of these transcription factors results in leukemic transformation (Sokalski et al., 2011). In this regard, induced expression of SPIC by RAG DSBs permits for stage-specific and transient inhibition of PU.1 (and SPIB). SPIC expression is expected to be lost after RAG DSBs are repaired and associated DDR signaling is terminated. The reduction in SPIC would allow PU.1 (and SPIB) to rebind to chromatin and resume transcriptional activities necessary for mature $B$ cell function. Thus, RAG DSBs regulate a temporary suppression of PU.1 to promote transition from large to small pre-B cells and then permit continued transition to antibody-producing mature $B$ cells.

PU.1 forms heterodimeric complexes with IRF4 or IRF8 to promote transcription (Brass et al., 1996; Heinz et al., 2010; Pongubala et al., 1992). As such, combined loss of IRF4 and IRF8 results in similar abnormalities in $\mathrm{B}$ cell development as loss of PU.1 (Lu et al., 2003; Ma et al., 2006). SPIC binds the same DNA sequence as PU.1 but has a distinct protein-interaction domain and does not bind IRF4 or IRF8 (Carlsson et al., 2003). Thus, SPIC could mediate suppression of transcription simply through displacement of PU.1 and loss of associated transcription activation machinery (i.e., IRF4). Displacement of the PU.1/ IRF4 complex alone, though, may be insufficient to repress transcription as this is not expected to result in rapid changes in histone modifications or RNA polymerase activity, which drive gene expression. Alternatively, in a manner similar to PU.1, SPIC may effect transcriptional inhibition by recruiting additional proteins to gene-regulatory elements. In this regard, we find that SPIC, but not PU.1, binds BCLAF1. BCLAF1 is not necessary for SPIC binding to chromatin but is required for transcriptional repression. On the basis of these findings, we propose that antagonism of PU. 1 activity is mediated by a SPIC-BCLAF1 complex that binds to chromatin and suppresses key PU.1regulated genes. Further studies are needed to determine the mechanism by which the SPIC-BCLAF1 complex regulates transcription (i.e., activity on histone epigenetics, RNA polymerase activity, and locus accessibility).

BCLAF1 was first identified as a transcriptional repressor but also functions as an activator to promote expression of p53 and cytokines in response to DNA damage (Kasof et al., 1999; Liu et al., 2007; Shao et al., 2016). BCLAF1 also has been identified as a component of the RNA splicing complex (Savage et al., 2014; Vohhodina et al., 2017). We find that in early B cells, BCLAF1 complexes with SPIC to repress gene expression in response to RAG-mediated DSBs. BCLAF1 chromatin binding nearly completely overlaps with SPIC-bound genomic regions. SPIC and BCLAF1 could bind DNA independently and then cooperatively suppress transcription. In this regard, in vitro studies have shown that BCLAF1 binds the interferon-stimulated response element (ISRE) (Qin et al., 2019). The sequence for binding of the PU.1/IRF4 heterodimer contains a portion of the ISRE site in series with an ETS motif. BCLAF1 and SPIC could bind this same sequence, or, alternatively, BCLAF1 may be recruited to gene regulatory regions through protein-protein interactions with SPIC, which binds ETS DNA sequences. The domains that govern SPIC and BCLAF1 protein interactions and DNA binding are currently being investigated.

We find that loss of BCLAF1 prevents RAG DSB- and SPICmediated repression of Syk mRNA expression. SYK is a key signaling molecule downstream of the pre-BCR and is required for the pre-BCR to promote proliferation of large pre-B cells (Clark et al., 2014; Herzog et al., 2009). We previously showed that in response to RAG DSBs, induction of SPIC suppresses pre-BCR signaling to enforce cell-cycle arrest in small pre-B cells (Bednarski et al., 2016). Thus, loss of BCLAF1 is expected to mitigate RAG DSB-induced inhibition of proliferation. Indeed, Bclaf1-deficient pre-B cells have increased cell cycle entry, and mice with $B$ cell-specific deletion of BCLAF1 have increased numbers of proliferating, large pre-B cells, consistent with increased SYK activity. Loss of BCLAF1 does not result in a complete block in $B$ cell development, which may reflect that additional mechanisms, such as p53, exist to regulate G1 arrest in small pre-B cells undergoing lg gene rearrangement.

In summary, we find that SPIC/BCLAF1 functions to modulate PU. 1 activity in pre-B cells. High activity of PU.1 promotes proliferation and expansion of large pre-B cells. As cells transition to small pre-B cell stage and initiate $I g l$ gene assembly, RAG DSBs induce expression of SPIC, which partners with BCLAF1, to oppose PU.1 activity resulting in gene expression changes, including suppression of Syk, that promote transition from large to small pre-B cells. After rearrangement of $l g l$ is completed and DSBs are repaired, termination of DDR signaling would result in cessation of SPIC/BCLAF1 activity and reestablishment of PU.1 transcriptional activation, which could support BCR signaling to drive transition to the immature $B$ cell stage. We propose that RAG DSB-dependent activation of SPIC/BCLAF1 functions as rheostat to titer PU.1 activity during early $B$ cell development. 


\section{STAR $\star$ METHODS}

Detailed methods are provided in the online version of this paper and include the following:

- KEY RESOURCES TABLE

- LEAD CONTACT AND MATERIALS AVAILABILITY

- EXPERIMENTAL MODEL AND SUBJECT DETAILS $\bigcirc$ Cell Lines and Primary Cultures

- METHOD DETAILS

o cDNA Expression and shRNA-Mediated Knock-down

Flow Cytometric Analyses and Cell Sorting

Cell Cycle Analysis

O Western Blot

O RT-PCR

O Chromatin Immunoprecipitation (ChIP) and ChIP-Seq

O Ultra-Low-Input Native ChIP

O RNA-Seq Analysis

O Tandem Affinity Purification and MS Analysis

- QUANTIFICATION AND STATISTICAL ANALYSIS

- DATA AND CODE AVAILABILITY

\section{SUPPLEMENTAL INFORMATION}

Supplemental Information can be found online at https://doi.org/10.1016/j. celrep.2019.09.026.

\section{ACKNOWLEDGMENTS}

This work was supported by NIH grants K08 Al102946 (J.J.B.), R01 CA193318 (N.M.), R01 CA227001 (N.M.), and R01 CA188286 (J.E.P.). J.J.B. is supported by the Alex's Lemonade Stand Foundation, the Foundation for Barnes-Jewish Hospital Cancer Frontier Fund, the Barnard Trust, and an American Society of Hematology Scholar Award. N.M. is an American Cancer Society Research Scholar and is supported by the Alvin J. Siteman Cancer Research Fund. We thank the Genome Technology Access Center (P30 CA91842 and UL1 TR000448) at Washington University School of Medicine for assistance with experiments. NIH grants to Regeneron (U01HG004085) and the CSD Consortium (U01HG004080) funded the KOMP Program.

\section{AUTHOR CONTRIBUTIONS}

D.S., L.S.W., W.Y., J.M.A., and R.J. performed experiments and data analyses. N.M. and J.E.P. provided expertise and assisted with data analyses. M.K. and K.M.M. provided mice and expertise for the studies. J.J.B. supervised the project, interpreted experiments, wrote the manuscript, and secured funding.

\section{DECLARATION OF INTERESTS}

The authors declare no competing interests.

Received: March 11, 2019

Revised: July 10, 2019

Accepted: September 9, 2019

Published: October 15, 2019

\section{REFERENCES}

Afgan, E., Baker, D., van den Beek, M., Blankenberg, D., Bouvier, D., Čech, M. Chilton, J., Clements, D., Coraor, N., Eberhard, C., et al. (2016). The Galaxy platform for accessible, reproducible and collaborative biomedical analyses: 2016 update. Nucleic Acids Res. 44 (W1), W3-W10.
Anderson, M.K., Weiss, A.H., Hernandez-Hoyos, G., Dionne, C.J., and Rothenberg, E.V. (2002). Constitutive expression of PU.1 in fetal hematopoietic progenitors blocks $\mathrm{T}$ cell development at the pro-T cell stage. Immunity 16 , 285-296.

Andley, U.P., Tycksen, E., McGlasson-Naumann, B.N., and Hamilton, P.D. (2018). Probing the changes in gene expression due to $\alpha$-crystallin mutations in mouse models of hereditary human cataract. PLoS ONE 13, e0190817.

Back, J., Allman, D., Chan, S., and Kastner, P. (2005). Visualizing PU.1 activity during hematopoiesis. Exp. Hematol. 33, 395-402.

Batista, C.R., Li, S.K., Xu, L.S., Solomon, L.A., and DeKoter, R.P. (2017). PU.1 regulates Ig light chain transcription and rearrangement in pre-B cells during $B$ cell development. J. Immunol. 198, 1565-1574.

Bednarski, J.J., Nickless, A., Bhattacharya, D., Amin, R.H., Schlissel, M.S., and Sleckman, B.P. (2012). RAG-induced DNA double-strand breaks signal through Pim2 to promote pre-B cell survival and limit proliferation. J. Exp. Med. 209, 11-17.

Bednarski, J.J., Pandey, R., Schulte, E., White, L.S., Chen, B.R., Sandoval, G.J., Kohyama, M., Haldar, M., Nickless, A., Trott, A., et al. (2016). RAG-mediated DNA double-strand breaks activate a cell type-specific checkpoint to inhibit pre-B cell receptor signals. J. Exp. Med. 213, 209-223.

Bemark, M., Mårtensson, A., Liberg, D., and Leanderson, T. (1999). Spi-C, a novel Ets protein that is temporally regulated during $B$ lymphocyte development. J. Biol. Chem. 274, 10259-10267.

Brass, A.L., Kehrli, E., Eisenbeis, C.F., Storb, U., and Singh, H. (1996). Pip, a lymphoid-restricted IRF, contains a regulatory domain that is important for autoinhibition and ternary complex formation with the Ets factor PU.1. Genes Dev. 10, 2335-2347.

Bredemeyer, A.L., Helmink, B.A., Innes, C.L., Calderon, B., McGinnis, L.M., Mahowald, G.K., Gapud, E.J., Walker, L.M., Collins, J.B., Weaver, B.K., et al. (2008). DNA double-strand breaks activate a multi-functional genetic program in developing lymphocytes. Nature 456, 819-823.

Brind'Amour, J., Liu, S., Hudson, M., Chen, C., Karimi, M.M., and Lorincz, M.C. (2015). An ultra-low-input native ChIP-seq protocol for genome-wide profiling of rare cell populations. Nat. Commun. 6, 6033.

Carlsson, R., Persson, C., and Leanderson, T. (2003). SPI-C, a PU-box binding ETS protein expressed temporarily during B-cell development and in macrophages, contains an acidic transactivation domain located to the $\mathrm{N}$-terminus. Mol. Immunol. 39, 1035-1043.

Clark, M.R., Mandal, M., Ochiai, K., and Singh, H. (2014). Orchestrating B cell lymphopoiesis through interplay of IL-7 receptor and pre-B cell receptor signalling. Nat. Rev. Immunol. 14, 69-80.

Dakic, A., Wu, L., and Nutt, S.L. (2007). Is PU.1 a dosage-sensitive regulator of haemopoietic lineage commitment and leukaemogenesis? Trends Immunol. $28,108-114$

DeKoter, R.P., Lee, H.J., and Singh, H. (2002). PU.1 regulates expression of the interleukin-7 receptor in lymphoid progenitors. Immunity 16, 297-309.

DeMicco, A., Reich, T., Arya, R., Rivera-Reyes, A., Fisher, M.R., and Bassing, C.H. (2016). Lymphocyte lineage-specific and developmental stage specific mechanisms suppress cyclin D3 expression in response to DNA double strand breaks. Cell Cycle 15, 2882-2894.

Desiderio, S., Lin, W.C., and Li, Z. (1996). The cell cycle and V(D)J recombination. Curr. Top. Microbiol. Immunol. 217, 45-59.

Eng, J.K., McCormack, A.L., and Yates, J.R. (1994). An approach to correlate tandem mass spectral data of peptides with amino acid sequences in a protein database. J. Am. Soc. Mass Spectrom. 5, 976-989.

Fugmann, S.D., Lee, A.I., Shockett, P.E., Villey, I.J., and Schatz, D.G. (2000). The RAG proteins and V(D)J recombination: complexes, ends, and transposition. Annu. Rev. Immunol. 18, 495-527.

Haldar, M., Kohyama, M., So, A.Y.-L., Wumesh, K.C., Wu, X., Briseno, C.G., Satpathy, A.T., Kretzer, N.M., Rajasekaran, N.S., Wang, L., et al. (2014). Heme-mediated BACH1 degradation induces SPI-C to promote monocyte differentiation into iron-recycling macrophages. Cell 156, 1223-1234. 
Hashimoto, S., Nishizumi, H., Hayashi, R., Tsuboi, A., Nagawa, F., Takemori, T., and Sakano, H. (1999). Prf, a novel Ets family protein that binds to the PU.1 binding motif, is specifically expressed in restricted stages of B cell development. Int. Immunol. 11, 1423-1429.

Heinz, S., Benner, C., Spann, N., Bertolino, E., Lin, Y.C., Laslo, P., Cheng, J.X., Murre, C., Singh, H., and Glass, C.K. (2010). Simple combinations of lineagedetermining transcription factors prime cis-regulatory elements required for macrophage and B cell identities. Mol. Cell 38, 576-589.

Helmink, B.A., and Sleckman, B.P. (2012). The response to and repair of RAGmediated DNA double-strand breaks. Annu. Rev. Immunol. 30, 175-202.

Herzog, S., Reth, M., and Jumaa, H. (2009). Regulation of B-cell proliferation and differentiation by pre-B-cell receptor signalling. Nat. Rev. Immunol. 9, 195-205.

Hobeika, E., Thiemann, S., Storch, B., Jumaa, H., Nielsen, P.J., Pelanda, R., and Reth, M. (2006). Testing gene function early in the B cell lineage in mb1cre mice. Proc. Natl. Acad. Sci. U S A 103, 13789-13794.

Huang, D., Sherman, B.T., Zheng, X., Yang, J., Imamichi, T., Stephens, R., and Lempicki, R.A. (2009). Extracting biological meaning from large gene lists with DAVID. Curr. Protoc. Bioinformatics Chapter 13, Unit 13.11.

Johnson, K., Hashimshony, T., Sawai, C.M., Pongubala, J.M., Skok, J.A., Aifantis, I., and Singh, H. (2008). Regulation of immunoglobulin light-chain recombination by the transcription factor IRF-4 and the attenuation of interleukin-7 signaling. Immunity 28, 335-345.

Kasof, G.M., Goyal, L., and White, E. (1999). Btf, a novel death-promoting transcriptional repressor that interacts with Bcl-2-related proteins. Mol. Cell. Biol. 19, 4390-4404.

Langmead, B., and Salzberg, S.L. (2012). Fast gapped-read alignment with Bowtie 2. Nat. Methods 9, 357-359.

Law, C.W., Chen, Y., Shi, W., and Smyth, G.K. (2014). voom: Precision weights unlock linear model analysis tools for RNA-seq read counts. Genome Biol. 15, R29.

Lawrence, M., Huber, W., Pagès, H., Aboyoun, P., Carlson, M., Gentleman, R., Morgan, M.T., and Carey, V.J. (2013). Software for computing and annotating genomic ranges. PLoS Comput. Biol. 9, e1003118.

Lerdrup, M., Johansen, J.V., Agrawal-Singh, S., and Hansen, K. (2016). An interactive environment for agile analysis and visualization of ChIP-sequencing data. Nat. Struct. Mol. Biol. 23, 349-357.

Li, S.K., Solomon, L.A., Fulkerson, P.C., and DeKoter, R.P. (2015). Identification of a negative regulatory role for Spi-C in the murine B cell lineage. J. Immunol. 194, 3798-3807.

Liu, H., Lu, Z.G., Miki, Y., and Yoshida, K. (2007). Protein kinase C delta induces transcription of the TP53 tumor suppressor gene by controlling death-promoting factor Btf in the apoptotic response to DNA damage. Mol. Cell. Biol. 27, 8480-8491.

Lu, R., Medina, K.L., Lancki, D.W., and Singh, H. (2003). IRF-4,8 orchestrate the pre-B-to-B transition in lymphocyte development. Genes Dev. 17, 17031708.

Ma, S., Turetsky, A., Trinh, L., and Lu, R. (2006). IFN regulatory factor 4 and 8 promote Ig light chain kappa locus activation in pre-B cell development. J. Immunol. 177, 7898-7904.

Maitra, S., and Atchison, M. (2000). BSAP can repress enhancer activity by targeting PU.1 function. Mol. Cell. Biol. 20, 1911-1922.

McPherson, J.P., Sarras, H., Lemmers, B., Tamblyn, L., Migon, E., MatysiakZablocki, E., Hakem, A., Azami, S.A., Cardoso, R., Fish, J., et al. (2009). Essential role for Bclaf1 in lung development and immune system function. Cell Death Differ. 16, 331-339.

Mosammaparast, N., Kim, H., Laurent, B., Zhao, Y., Lim, H.J., Majid, M.C., Dango, S., Luo, Y., Hempel, K., Sowa, M.E., et al. (2013). The histone demethylase LSD1/KDM1A promotes the DNA damage response. J. Cell Biol. 203, 457-470.

Nakatani, Y., and Ogryzko, V. (2003). Immunoaffinity purification of mammalian protein complexes. Methods Enzymol. 370, 430-444.
Nerlov, C., Querfurth, E., Kulessa, H., and Graf, T. (2000). GATA-1 interacts with the myeloid PU.1 transcription factor and represses PU.1-dependent transcription. Blood 95, 2543-2551.

Nutt, S.L., Metcalf, D., D’Amico, A., Polli, M., and Wu, L. (2005). Dynamic regulation of PU.1 expression in multipotent hematopoietic progenitors. J. Exp. Med. 201, 221-231.

Ochiai, K., Maienschein-Cline, M., Mandal, M., Triggs, J.R., Bertolino, E. Sciammas, R., Dinner, A.R., Clark, M.R., and Singh, H. (2012). A self-reinforcing regulatory network triggered by limiting IL-7 activates pre-BCR signaling and differentiation. Nat. Immunol. 13, 300-307.

Pang, S.H., Carotta, S., and Nutt, S.L. (2014). Transcriptional control of pre-B cell development and leukemia prevention. Curr. Top. Microbiol. Immunol. $381,189-213$.

Pang, S.H., Minnich, M., Gangatirkar, P., Zheng, Z., Ebert, A., Song, G., Dickins, R.A., Corcoran, L.M., Mullighan, C.G., Busslinger, M., et al. (2016). PU.1 cooperates with IRF4 and IRF8 to suppress pre-B-cell leukemia. Leukemia $30,1375-1387$.

Pang, S.H.M., de Graaf, C.A., Hilton, D.J., Huntington, N.D., Carotta, S., Wu L., and Nutt, S.L. (2018). PU.1 is required for the developmental progression of multipotent progenitors to common lymphoid progenitors. Front. Immunol. 9, 1264.

Polli, M., Dakic, A., Light, A., Wu, L., Tarlinton, D.M., and Nutt, S.L. (2005). The development of functional B lymphocytes in conditional PU.1 knock-out mice. Blood 106, 2083-2090.

Pongubala, J.M., Nagulapalli, S., Klemsz, M.J., McKercher, S.R., Maki, R.A., and Atchison, M.L. (1992). PU.1 recruits a second nuclear factor to a site important for immunoglobulin kappa $3^{\prime}$ enhancer activity. Mol. Cell. Biol. 12, 368-378.

Qin, C., Zhang, R., Lang, Y., Shao, A., Xu, A., Feng, W., Han, J., Wang, M., He, W., Yu, C., and Tang, J. (2019). Bclaf1 critically regulates the type I interferon response and is degraded by alphaherpesvirus US3. PLoS Pathog. 15, e1007559.

Quinlan, A.R., and Hall, I.M. (2010). BEDTools: a flexible suite of utilities for comparing genomic features. Bioinformatics 26, 841-842.

Rajewsky, K. (1996). Clonal selection and learning in the antibody system. Nature $381,751-758$

Robinson, M.D., McCarthy, D.J., and Smyth, G.K. (2010). edgeR: a Bioconductor package for differential expression analysis of digital gene expression data. Bioinformatics 26, 139-140.

Rogers, J.H., Owens, K.S., Kurkewich, J., Klopfenstein, N., Iyer, S.R., Simon, M.C., and Dahl, R. (2016). E2A antagonizes PU.1 activity through inhibition of DNA binding. BioMed Res. Int. 2016, 3983686.

Rolink, A., Kudo, A., Karasuyama, H., Kikuchi, Y., and Melchers, F. (1991) Long-term proliferating early pre B cell lines and clones with the potential to develop to surface Ig-positive, mitogen reactive $\mathrm{B}$ cells in vitro and in vivo. EMBO J. 10, 327-336.

Rolink, A.G., Winkler, T., Melchers, F., and Andersson, J. (2000). Precursor B cell receptor-dependent $B$ cell proliferation and differentiation does not require the bone marrow or fetal liver environment. J. Exp. Med. 191, 23-32.

Rosenbauer, F., Wagner, K., Kutok, J.L., Iwasaki, H., Le Beau, M.M., Okuno, Y., Akashi, K., Fiering, S., and Tenen, D.G. (2004). Acute myeloid leukemia induced by graded reduction of a lineage-specific transcription factor, PU.1. Nat. Genet. 36, 624-630.

Rosenbauer, F., Owens, B.M., Yu, L., Tumang, J.R., Steidl, U., Kutok, J.L., Clayton, L.K., Wagner, K., Scheller, M., Iwasaki, H., et al. (2006). Lymphoid cell growth and transformation are suppressed by a key regulatory element of the gene encoding PU.1. Nat. Genet. 38, 27-37.

Saldanha, A.J. (2004). Java Treeview - extensible visualization of microarray data. Bioinformatics 20, 3246-3248.

Savage, K.I., Gorski, J.J., Barros, E.M., Irwin, G.W., Manti, L., Powell, A.J., Pellagatti, A., Lukashchuk, N., McCance, D.J., McCluggage, W.G., et al. (2014). Identification of a BRCA1-mRNA splicing complex required for efficient DNA repair and maintenance of genomic stability. Mol. Cell 54, 445-459. 
Schwarzenbach, H., Newell, J.W., and Matthias, P. (1995). Involvement of the Ets family factor PU.1 in the activation of immunoglobulin promoters. J. Biol. Chem. 270, 898-907.

Schweitzer, B.L., and DeKoter, R.P. (2004). Analysis of gene expression and Ig transcription in PU.1/Spi-B-deficient progenitor B cell lines. J. Immunol. 172, 144-154.

Scott, E.W., Simon, M.C., Anastasi, J., and Singh, H. (1994). Requirement of transcription factor PU.1 in the development of multiple hematopoietic lineages. Science 265, 1573-1577.

Scott, E.W., Fisher, R.C., Olson, M.C., Kehrli, E.W., Simon, M.C., and Singh, H. (1997). PU.1 functions in a cell-autonomous manner to control the differentiation of multipotential lymphoid-myeloid progenitors. Immunity 6, 437-447.

Shao, Z., Zhang, Y., Yuan, G.C., Orkin, S.H., and Waxman, D.J. (2012). MAnorm: a robust model for quantitative comparison of ChIP-Seq data sets. Genome Biol. 13, R16.

Shao, A.W., Sun, H., Geng, Y., Peng, Q., Wang, P., Chen, J., Xiong, T., Cao, R., and Tang, J. (2016). Bclaf1 is an important NF- $\kappa B$ signaling transducer and $\mathrm{C} / \mathrm{EBP} \beta$ regulator in DNA damage-induced senescence. Cell Death Differ. 23, 865-875.

Sokalski, K.M., Li, S.K., Welch, I., Cadieux-Pitre, H.A., Gruca, M.R., and DeKoter, R.P. (2011). Deletion of genes encoding PU.1 and Spi-B in B cells impairs differentiation and induces pre-B cell acute lymphoblastic leukemia. Blood 118, 2801-2808.

Solomon, L.A., Li, S.K., Piskorz, J., Xu, L.S., and DeKoter, R.P. (2015). Genome-wide comparison of PU.1 and Spi-B binding sites in a mouse B lymphoma cell line. BMC Genomics 16, 76.

Steinel, N.C., Lee, B.S., Tubbs, A.T., Bednarski, J.J., Schulte, E., Yang-lott, K.S., Schatz, D.G., Sleckman, B.P., and Bassing, C.H. (2013). The ataxia telan- giectasia mutated kinase controls Igк allelic exclusion by inhibiting secondary Vк-to-Jк rearrangements. J. Exp. Med. 210, 233-239.

Stewart, S.A., Dykxhoorn, D.M., Palliser, D., Mizuno, H., Yu, E.Y., An, D.S., Sabatini, D.M., Chen, I.S., Hahn, W.C., Sharp, P.A., et al. (2003). Lentivirus-delivered stable gene silencing by RNAi in primary cells. RNA 9, 493-501.

Su, G.H., Chen, H.M., Muthusamy, N., Garrett-Sinha, L.A., Baunoch, D., Tenen, D.G., and Simon, M.C. (1997). Defective B cell receptor-mediated responses in mice lacking the Ets protein, Spi-B. EMBO J. 16, 7118-7129.

Vohhodina, J., Barros, E.M., Savage, A.L., Liberante, F.G., Manti, L., Bankhead, P., Cosgrove, N., Madden, A.F., Harkin, D.P., and Savage, K.I. (2017). The RNA processing factors THRAP3 and BCLAF1 promote the DNA damage response through selective mRNA splicing and nuclear export. Nucleic Acids Res. 45, 12816-12833.

Wossning, T., Herzog, S., Köhler, F., Meixlsperger, S., Kulathu, Y., Mittler, G., Abe, A., Fuchs, U., Borkhardt, A., and Jumaa, H. (2006). Deregulated Syk inhibits differentiation and induces growth factor-independent proliferation of pre-B cells. J. Exp. Med. 203, 2829-2840.

Ye, M., Ermakova, O., and Graf, T. (2005). PU.1 is not strictly required for B cell development and its absence induces a B-2 to B-1 cell switch. J. Exp. Med. 202, 1411-1422.

Zhang, Y., Liu, T., Meyer, C.A., Eeckhoute, J., Johnson, D.S., Bernstein, B.E., Nusbaum, C., Myers, R.M., Brown, M., Li, W., and Liu, X.S. (2008). Modelbased analysis of ChIP-seq (MACS). Genome Biol. 9, R137.

Zhao, S., Guo, Y., Sheng, Q., and Shyr, Y. (2014). Advanced heat map and clustering analysis using heatmap3. BioMed Res. Int. 2014, 986048.

Zhu, X., Schweitzer, B.L., Romer, E.J., Sulentic, C.E., and DeKoter, R.P. (2008). Transgenic expression of Spi-C impairs B-cell development and function by affecting genes associated with BCR signaling. Eur. J. Immunol. 38, 2587-2599. 


\section{STAR $\star M E T H O D S$}

\section{KEY RESOURCES TABLE}

\begin{tabular}{|c|c|c|}
\hline REAGENT or RESOURCE & SOURCE & IDENTIFIER \\
\hline \multicolumn{3}{|l|}{ Antibodies } \\
\hline APC human CD25 Clone BC96 & BioLegend & Cat\# 302610; RRID: AB_314280 \\
\hline biotin conjugated anti-hCD2 & BD Biosciences & Cat\# 555325; RRID: AB_395732 \\
\hline PE- anti-hCD25 Clone BC96 & BioLegend & Cat\# 302605; RRID: AB_314275 \\
\hline FITC-conjugated anti-CD45R/B220 (clone RA3-6B2) & BD Biosciences & Cat\# 553088; RRID: AB_394618 \\
\hline PE-conjugated anti-CD43 (clone S7) & BD Biosciences & Cat\# 553271: RRID: AB_394748 \\
\hline FITC-conjugated anti-CD43 (clone S7) & BD Biosciences & Cat\# 553270; RRID: AB_394747 \\
\hline PE-Cy7-conjugated anti-CD45/B220 (clone RA3-6B2) & BD Biosciences & Cat \# 552772: RRID: AB_394458 \\
\hline allophycocyanin (APC)-conjugated anti-IgM (clone II/41) & BD Biosciences & Cat \# 550676; RRID: AB_398464 \\
\hline PE-conjugated anti-hCD2 & BD Biosciences & Cat\# 555327; RRID: AB_395734 \\
\hline APC-conjugated anti-hCD2 & BD Biosciences & Cat\# 560642; RRID: AB_1727443 \\
\hline Anti-SYK (clone D1I5Q) & Cell Signaling Technology & Cat\# 12358; RRID: AB_2687923 \\
\hline Anti-BCLAF1 antibody (A300-608A) & Bethyl Laboratories & Cat\# A300-608A; RRID: AB_513581 \\
\hline PU.1 (PA5-17505) & Thermo Fisher & Cat\# 17505; RRID: AB_10989141 \\
\hline Anti-GAPDH & Cell Signaling & Cat\# 5174; RRID: AB_10622025 \\
\hline anti-FLAG (clone M2) & Sigma & Cat\# 1804; RRID: AB_262044 \\
\hline HRP-conjugated anti-mouse lgG & Cell Signaling & Cat \# 7074; RRID: AB_2099233 \\
\hline HRP-conjugated anti-rabbit lgG & Cell Signaling & Cat\# 7065; RRID: AB_10890862 \\
\hline Anti-HA & Abcam & Cat\# ab9110; RRID: AB_307019 \\
\hline control rabbit IgG & Millipore & Cat\# 06-371; RRID: AB_390146 \\
\hline \multicolumn{3}{|l|}{ Chemicals, Peptides, and Recombinant Proteins } \\
\hline SuperScriptll & Life Technologies & $18064-014$ \\
\hline Brilliant II SYBR Green & Agilent & 600828 \\
\hline Interleukin-7 (IL-7) & Miltenyi Biotec & $130-098-222$ \\
\hline Imatinib & Novartis & $00078-0438-15$ \\
\hline Lipofectamine 2000 & Life Technologies & $11668-019$ \\
\hline PEG-8000 & Fisher & $\mathrm{P} 156-500$ \\
\hline Sequabrene & Sigma & S 2667 \\
\hline ATM inhibitor KU55933 & Tocris & 3544 \\
\hline Micrococcal nuclease & New England Biolabs & M0247S \\
\hline \multicolumn{3}{|l|}{ Critical Commercial Assays } \\
\hline RNeasy & QIAGEN & 74104 \\
\hline Protein A Dynabeads & Thermo Fisher Scientific & $10002 D$ \\
\hline QIAquick PCR purification kit & QIAGEN & 28106 \\
\hline Anti-biotin magnetic beads & Miltenyi Biotec & $130-090-485$ \\
\hline Anti-hCD25 magnetic beads & Miltenyi Biotec & $130-092-983$ \\
\hline Anti-hCD2 magnetic beads & Miltenyi Biotec & $130-091-114$ \\
\hline High sensitivity DNA ChiPs & Agilent Technologies & $5067-4626$ \\
\hline Magnetic Separation columns & Miltenyi Biotec & $130-042-201$ \\
\hline ECL & Pierce & 32209 \\
\hline ECL Prime & GE Healthcare & RPN2232 \\
\hline FITC BrdU Flow Kit & BD Bioscience & 559619 \\
\hline \multicolumn{3}{|l|}{ Deposited Data } \\
\hline ChiP-seq & This paper & NCBI GEO \#: GSE129130 (subseries: GSE129124) \\
\hline RNA-seq & This paper & NCBI GEO \#: GSE129130 (subseries: GSE129129) \\
\hline
\end{tabular}




\begin{tabular}{|c|c|c|}
\hline Continued & & \\
\hline REAGENT or RESOURCE & SOURCE & IDENTIFIER \\
\hline \multicolumn{3}{|l|}{ Experimental Models: Cell Lines } \\
\hline $\mathrm{Art}^{-1-}: B c / 2$ abl pre-B cell & Barry Sleckman & $\mathrm{N} / \mathrm{A}$ \\
\hline $\mathrm{Rag}^{-1-}: B c / 2$ abl pre-B cell & Barry Sleckman & $\mathrm{N} / \mathrm{A}$ \\
\hline PlatE & Cell Biolabs, Inc & RV-101 \\
\hline \multicolumn{3}{|l|}{ Experimental Models: Organisms/Strains } \\
\hline Mb1-cre (Cd79a $\left.{ }^{\text {tm1(cre)Reth }}\right)$ mice & Jackson Laboratory & 20505 \\
\hline Bclaf1 ${ }^{f / f}$ mice & KOMP Repository & Bclaft $1^{\text {tm1a }}$ \\
\hline $\operatorname{Rag1}^{-1-}: \mu \operatorname{lgh}: B c / 2$ & Barry Sleckman & N/A \\
\hline $\mathrm{Art}^{-1-}: \mu \operatorname{lgh}: B c / 2$ & Barry Sleckman & $\mathrm{N} / \mathrm{A}$ \\
\hline B6.Cg-Tg(ACTFLPe)9205Dym/J & Jackson Laboratory & 5703 \\
\hline Spic igfp/igfp & Kenneth Murphy & N/A \\
\hline \multicolumn{3}{|l|}{ Oligonucleotides } \\
\hline Primers are listed in Table S5 & This paper & $\mathrm{N} / \mathrm{A}$ \\
\hline \multicolumn{3}{|l|}{ Recombinant DNA } \\
\hline MSCV-hCD2-mir30 vector & Mark Schlissel & N/A \\
\hline pFLRU-TRE-FLAG-HA-PU.1-Ubc-rtTA-IRES-Thy1.2 & This paper & N/A \\
\hline pFLRU-TRE-FLAG-HA-SPIC-Ubc-rtTA-IRES-Thy 1.2 & This paper & N/A \\
\hline pCMV-VSV-G & Stewart et al., 2003 & Addgene \#8454 \\
\hline pCMV-d8.2R dvpr & Stewart et al., 2003 & Addgene \#8455 \\
\hline \multicolumn{3}{|l|}{ Software and Algorithms } \\
\hline Bowtie v. 1.1.2 & $\begin{array}{l}\text { Langmead and Salzberg, } \\
2012\end{array}$ & $\begin{array}{l}\text { http://bowtie-bio.sourceforge. net/bowtie2/index. } \\
\text { shtml RRID:SCR_005476 }\end{array}$ \\
\hline MACS version 2 & Zhang et al., 2008 & $\begin{array}{l}\text { http://liulab.dfci.harvard.edu/MACS/ } \\
\text { RRID:SCR_013291 }\end{array}$ \\
\hline Galaxy V18.09 & Afgan et al., 2016 & https://usegalaxy.org RRID:SCR_006281 \\
\hline GenomicRanges & Lawrence et al., 2013 & $\begin{array}{l}\text { https://www.bioconductor.org/packages//2.10/ } \\
\text { bioc/html/GenomicRanges.html } \\
\text { RRID:SCR_000025 }\end{array}$ \\
\hline Bedtools V2.25.0 & Quinlan and Hall, 2010 & $\begin{array}{l}\text { https://github.com/arq5x/bedtools2. RRID: } \\
\text { SCR_006646 }\end{array}$ \\
\hline EdgeR- TMM & Robinson et al., 2010 & $\begin{array}{l}\text { http://bioconductor.org/biocLite.R } \\
\text { RRID:SCR_012802 }\end{array}$ \\
\hline Limma-Voom & Law et al., 2014 & $\begin{array}{l}\text { https://omictools.com/limma-tool } \\
\text { RRID:SCR_010943 }\end{array}$ \\
\hline TreeView Version 1.1.6r4 & Saldanha, 2004 & $\begin{array}{l}\text { https://bitbucket.org/TreeView3Dev/treeview3/ } \\
\text { RRID:SCR_016916 }\end{array}$ \\
\hline Heatmap3 & Zhao et al., 2014 & $\begin{array}{l}\text { https://bioconductor.org/packages/release/bioc/ } \\
\text { html/heatmaps.html }\end{array}$ \\
\hline DAVID (v.6.8) & Huang et al., 2009 & https://david.ncifcrf.gov RRID:SCR_001881 \\
\hline EaSeq (v1.111) & Lerdrup et al., 2016 & http://easeq.net \\
\hline MAnorm & Shao et al., 2012 & $\begin{array}{l}\text { http://bcb.dfci.harvard.edu/ gcyuan/MAnorm/ } \\
\text { MAnorm.htm RRID:SCR_010869 }\end{array}$ \\
\hline Prism 8 (v8.0.2) & GraphPad Software & https://www.graphpad.com \\
\hline
\end{tabular}

\section{LEAD CONTACT AND MATERIALS AVAILABILITY}

Further information and request for resources and reagents should be directed to the Lead Contact, Jeff Bednarski (bednarski_j@ wustl.edu). All unique/stable reagents, including plasmids and mouse lines, are available from the Lead Contact with a completed Materials Transfer Agreement. 


\section{EXPERIMENTAL MODEL AND SUBJECT DETAILS}

Mice: All mice were bred and maintained under specific pathogen-free conditions at the Washington University School of Medicine and were handled in accordance to the guidelines set forth by the Division of Comparative Medicine of Washington University. Mb1cre $\left(C d 79 a^{t m 1(c r e) R e t h}\right)$ mice were purchased from The Jackson Laboratory. Bclaf1 ${ }^{f / f}$ mice were generated by the trans-NIH Knock-Out Mouse Project (KOMP) and obtained from the KOMP Repository (www.komp.org). Rag $1^{-1-}: \mu l g h: B c / 2$ and Art ${ }^{-1-}: \mu l g h: B c / 2$ were generated as previously described (Bednarski et al., 2012, 2016). Spic ${ }^{\text {igfp/igfp }}$ (Spic ${ }^{\text {tm2.1Kmm})}$ were kindly provided by K. M. Murphy

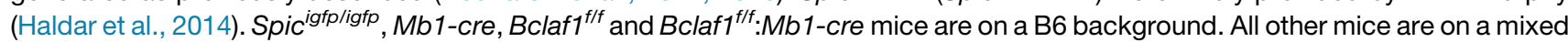
genetic background. Both sexes were used equivalently in all experiments. In vivo studies were conducted on 4-5 week old mice.

\section{Cell Lines and Primary Cultures}

$\operatorname{Rag}^{-1-}: B c / 2$ and $A t^{-1-}: B c / 2$ abl pre-B cells were a gift from Barry Sleckman. Cell lines were authenticated by genotyping. To induce cell cycle arrest and induction of RAG DSBs, cell lines were treated with $3 \mu \mathrm{M}$ imatinib for indicated times (Bredemeyer et al., 2008). Primary pre-B cell cultures were generated by culturing bone marrow from 4-6 week old mice at $2 \times 10^{6}$ cells $/ \mathrm{mL}$ in media containing $5 \mathrm{ng} / \mathrm{mL}$ of IL-7 (Miltenyi Biotec) for 7-10 days (Bednarski et al., 2012, 2016). Both sexes were used equivalently in all experiments. For IL-7 withdrawal experiments, cells were resuspended in media without IL-7 and maintained at $2 \times 10^{6}$ cells $/ \mathrm{mL}$ for the indicated times. ATM inhibitor KU55933 (15 $\mu \mathrm{M}$; Tocris) was added to cultures at time of addition of imatinib or IL-7 withdrawal.

\section{METHOD DETAILS}

cDNA Expression and shRNA-Mediated Knock-down cDNAs for SPIC and PU.1 with 5' FLAG-HA tag were individually cloned into the pFLRU-TRE-Ubc-rtTA-IRES-Thy1.2 lentiviral vector. shRNA targeting Bclaf1 (sequence: 5'-CCTCATAGTCCTTCAC CTATT-3') was cloned into the MSCV-hCD2-mir30 vector (Bednarski et al., 2012). Retrovirus was produced in platE cells by transfection of the retroviral plasmid with Lipofectamine 2000 (Life Technologies) according to the manufacturer's protocol. Lentivirus was produced in 293T cells by transfection of the lentiviral plasmid along with pCMV-VZV-G and pCMV-d8.2R plasmids with Lipofectamine 2000 (Stewart et al., 2003). Viral supernatant was collected and pooled from 24-72 hours after transfection. Viral supernatant was used immediately to transduce cells or was concentrated prior to transduction. To concentrate viral particles, PEG-8000 (Sigma; final concentration 8\%) was added to viral supernatant followed by incubation at $4{ }^{\circ} \mathrm{C}$ overnight and centrifugation at 2500 RPM for 20 minutes. Precipitated virus was resuspended at $300 x$ concentration in sterile PBS. Pre-B cells were transduced with unconcentrated virus ( $10 \times 10^{6}$ cells in $1 \mathrm{~mL}$ viral supernatant) or with concentrated virus $\left(40 \times 10^{6}\right.$ in $1 \mathrm{~mL}$ with $10 \times$ viral particles) in media with polybrene $(5 \mu \mathrm{g} / \mathrm{ml}$; Sigma) by centrifugation for 90 min at 1300 RPM at room temperature. Four hours later fresh media was added and the cells were incubated overnight. Virus-containing media was removed and cells were cultured in fresh media $\left(2 \times 10^{6} / \mathrm{ml}\right)$. Cells expressing the retrovirus construct were identified by flow cytometric assessment of hCD25 or hCD2 expression using a FACSCalibur (BD Biosciences). Transduced cells were sorted using biotin conjugated anti-hCD2 or anti-hCD25 (BD Biosciences) and anti-biotin magnetic beads (Miltenyi Biotec) on MS columns (Miltenyi Biotec) according to the manufacturer's protocol.

\section{Flow Cytometric Analyses and Cell Sorting}

Flow cytometric analyses were performed on a FACSCalibur or BD LSRFortessa (BD Biosciences). Sorting was conducted on a Sony Sy3200 through the Siteman Cancer Center Flow Cytometry Core Facility. Fluorescein isothiocyanate (FITC)-conjugated antiCD45R/B220 (clone RA3-6B2), phycoerythrin (PE)-conjugated anti-CD43 (clone S7), FITC-conjugated anti-CD43 (clone S7), PECy7-conjugated anti-CD45/B220 (clone RA3-6B2), allophycocyanin (APC)-conjugated anti-lgM (clone II/41), APC-conjugated anti-hCD2, and PE-conjugated anti-hCD2 were purchased from BD Biosciences. PE-conjugated anti-hCD25 (clone BC96) and APC-conjugated anti-hCD25 (clone BC96) were purchased from BioLegend.

\section{Cell Cycle Analysis}

To assess pre-BCR driven proliferation, pre-B cells were resuspended in media without IL-7 and maintained at $2 \times 10^{6} \mathrm{cells} / \mathrm{mL}$. Twenty-four hours after removal from IL-7 cells were pulsed BrdU for two hours using the BrdU-FITC kit (BD Biosciences) per the manufacturer's instructions. DNA content was assessed by 7AAD (BD Biosciences).

\section{Western Blot}

Western blots were done on whole cell lysates (Bednarski et al., 2016). Anti-SYK (clone D1I5Q) and anti-GAPDH (clone D16H11) antibodies were from Cell Signaling Technology. Anti-BCLAF1 antibody (A300-608A) was from Bethyl Laboratories. Anti-PU.1 (PA517505) was from Thermo Fisher Scientific. Anti-FLAG (clone M2) was from Sigma. Secondary reagents were horseradish peroxidase (HRP)-conjugated anti-mouse IgG (Cell Signaling; catalog \# 7076) or anti-rabbit IgG (Cell Signaling; catalog \# 7074). Westerns were developed with ECL (Pierce) and ECL Prime (GE Healthcare). 


\section{RT-PCR}

For genomic DNA isolation, cells were lysed in lysis buffer (100 mM TRIS pH8.5, 5 mM EDTA, 200mM NaCl and 0.2\% SDS) and DNA was precipitated by addition of isopropanol, washed with $70 \%$ ethanol and then resuspended in Tris-EDTA buffer (Bredemeyer et al., 2008). RNA was isolated using RNeasy (QIAGEN) and reversed transcribed using a polyT primer with SuperScriptll (Life Technologies) according to the manufacturers' protocol. RT-PCR was performed using Brilliant II SYBR Green (Agilent) and acquired on an

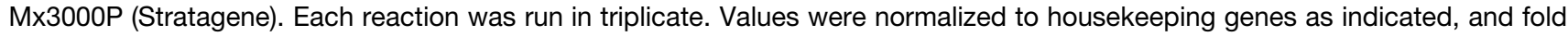
change was determined by the $\Delta \Delta$ cycle threshold method. Primer sequences are listed in Table S5.

\section{Chromatin Immunoprecipitation (ChIP) and ChIP-Seq}

ChIP was performed using anti-PU.1 (PA5-17505, Thermo Fisher Scientific), anti-FLAG (clone M2, Sigma), anti-HA (ab9110, Abcam), anti-BCLAF1 (A300-608A, Bethyl Laboratories), control rabbit IgG (Millipore) and control mouse IgG antibodies (clone P3.6.2.8.1, eBioscience) as previously described (Bednarski et al., 2016). Briefly, DNA was cross-linked with $2 \%$ formaldehyde for 10 min at room temp $\left(1 \times 10^{6} \mathrm{cells} / \mathrm{ml}\right)$. Reaction was stopped with $125 \mu \mathrm{M}$ Glycine. Cells were lysed with NP-40 and nuclei were frozen in liquid nitrogen then lysed with SDS. DNA was fragmented by sonicating with 30 s pulses for 60 cycles using a Bioruptor (Diagenode). DNA fragmentation was in the range of 200-500 bp and was monitored by agarose gel electrophoresis. Immunoprecipitation was performed with anti-PU.1 (1:100), anti-HA $(1 \mu \mathrm{g})$, anti-BCLAF1 $(2 \mu \mathrm{g})$, or control rabbit IgG and Protein A Dynabeads (Life Technologies). DNA was eluted, reverse cross-linked and then purified with QIAquick PCR purification kit (QIAGEN). For ChIP-PCR analysis, PCR was performed using Brilliant II SYBR Green (Agilent) and acquired on an Mx3000P (Stratagene). Primers are listed in Table S5. For ChIP-seq analysis, fragmented DNA was quantified using 2100 Bioanalyzer (Agilent Technologies) and DNA libraries were prepared using Illumina TruSeq. Sequencing was performed using an Illumina HiSeq 3000 by the Washington University Genome Technology Access Center. Input controls were used for all samples. FASTQ files were aligned to mm9 using Map with Bowtie for Illumina v. 1.1.2 to the reference genome (NCBI37/mm9) (Langmead and Salzberg, 2012). MACS version 2 was used to call peaks with a tag size set to 45 , band width of 300 and a p value of $1 \times 10^{-5}$ (Zhang et al., 2008). Input. bed files of total reads for MM-ChIP were generated using Convert from BAM to BED tool v0.1.0 in Galaxy V18.09 (Afgan et al., 2016). Promoter regions were defined as regions extending $12 \mathrm{~kb}$ upstream of transcription start site. R package (GenomicRanges) and Bedtools V2.25.0 were used to determine overlapping ChIP peaks (Lawrence et al., 2013; Quinlan and Hall, 2010). MAnorm using parameters -w 300-s1 50-s2 50 was used to calculate normalized fold changes for each ChIP-seq comparison (Shao et al., 2012). A 1.5 fold change magnitude was used to separate enriched and unbiased peaks for each comparison. EaSeq v1.111 was used to generate ratiometric heatmaps from RPM-normalized ChIP-seq signal (Lerdrup et al., 2016). Data will be deposited in NCBI's Gene Expression Omnibus.

\section{Ultra-Low-Input Native ChIP}

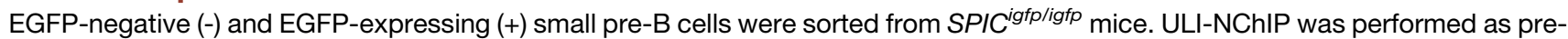
viously described (Brind'Amour et al., 2015). Briefly, chromatin was fragmented using micrococcal nuclease (New England Biolabs) at $37^{\circ} \mathrm{C}$ for 5 mins and diluted in complete immunoprecipitation buffer (20mM Tris- $\mathrm{HCl}$ pH 8.0, 2mM EDTA, $15 \mathrm{mM} \mathrm{NaCl,} 0.1 \%$ Triton $\mathrm{X}-100$, protease and phosphatase inhibitors). Fragmented chromatin was precleared with Protein A Dynabeads (Life Technologies). Immunoprecipitation was performed with anti-PU.1 (1:100), anti-BCLAF1 (10 $\mu \mathrm{g})$, or control rabbit IgG and Protein A Dynabeads (Life Technologies). The antibody-beads complex was washed with low salt (20mM Tris-HCl, pH 8.0, 0.1\%SDS, $1 \%$ Triton X-100, 0.1\% deoxycholate, $2 \mathrm{mM}$ EDTA and $150 \mathrm{mM} \mathrm{NaCl}$ ) and high salt (20mM Tris- $\mathrm{HCl}, \mathrm{pH} 8.0,0.1 \% \mathrm{SDS}, 1 \%$ Triton X-100, 0.1\% deoxycholate, $2 \mathrm{mM}$ EDTA and $300 \mathrm{mM} \mathrm{NaCl}$ ) buffer. DNA was eluted in high salt buffer. DNA was purified and ChIP-PCR was performed as above.

\section{RNA-Seq Analysis}

RNA was extracted using RNeasy Kit (QIAGEN). Libraries were prepared using Illumina TrueSeq Adpaters and paired-end sequencing was performed using an Illumina HiSeq 3000 by the Washington University Genome Technology Access Center according to the manufacturer's protocols. Sequencing data were analyzed as previously described (Andley et al., 2018). Briefly, RNA-seq reads were aligned to $\mathrm{mm} 9$ assembly with STAR version 2.0.4b1. Gene counts were derived from uniquely aligned unambiguous reads by Subread-featureCount version 1.4.5. Gene-level counts were imported into the R/Bioconductor package EdgeR and TMM normalization size factors were calculated to adjust for differences in library size (Robinson et al., 2010). Differential expression analysis was then performed to analyze for differences between conditions using the R/Bioconductor package limma-voom (Law et al., 2014). Results were filtered for only those genes with Benjamini-Hochberg false-discovery rate adjusted $p$ values less than or equal to 0.05. DAVID (Database for Annotation, Visualization and Integrated Discovery, v6.8) was used to test if differentially expressed genes resulted in perturbations in known Gene Ontology (GO) terms and KEGG pathways (Huang et al., 2009). Volcano plots were generated using R (ggplot2). Java TreeView Version 1.1.6r4 and R/Bioconductor package heatmap3 were used to display heatmaps (Saldanha, 2004; Zhao et al., 2014). DAVID was used to display annotated KEGG graphs across groups of samples for each GO term or KEGG pathway with a Benjamini-Hochberg false-discovery rate adjusted $p$ value $\leq 0.05$.

\section{Tandem Affinity Purification and MS Analysis}

FLAG-HA-tagged SPIC and PU.1 were immunoprecipitated using anti-FLAG antibody as previously described with the following modifications (Mosammaparast et al., 2013; Nakatani and Ogryzko, 2003). Cells were lysed lysis of cells $\left(1 \times 10^{9}\right.$ cells/1.5 ml) in 
TAP buffer (50 mM Tris, pH 7.9, $150 \mathrm{mM} \mathrm{NaCl}, 1 \% \mathrm{NP}-40$, and protease and phosphatase inhibitor cocktails (Sigma). The lysate was cleared by centrifugation and incubated with anti-FLAG beads $\left(40 \mu \mathrm{l} / 10^{9}\right.$ cells; clone M2; Sigma-Aldrich) for 4 hours. After extensive washing in the same buffer, bound material was eluted with FLAG peptide (Sigma-Aldrich) and analyzed by western blotting. Coomassie-stained bands were cut from SDS-PAGE and sent to Taplin Biological Mass Spectrometry Facility at Harvard Medical School (taplin.med.harvard.edu). In-gel trypsin digestion was performed and the detection of complexed proteins was done using Orbitrap ion-trap mass spectrometers (ThermoFisher Scientific). Interacting proteins were identified by matching protein database with acquired fragmentation pattern by using Sequest (ThermoFisher Scientific) (Eng et al., 1994).

\section{QUANTIFICATION AND STATISTICAL ANALYSIS}

RNA-seq and ChIP-seq were analyzed for statistical significance using the software packages described above. For all other analyses, statistics and figures were generated using Prism 8 (v8.0.2). P values were generated via Student's t test (unpaired, two-tailed). Error bars are SE. ${ }^{*} p$ value $\leq 0.05,{ }^{* *} p$ value $\leq 0.01,{ }^{* \star *} p$ value $\leq 0.001,{ }^{\star * \star *} p$ value $\leq 0.0001$.

\section{DATA AND CODE AVAILABILITY}

The ChIP-seq and RNA-seq data generated during this study are available at NCBI Gene Expression Omnibus under accession number GEO: GSE129130. 
Cell Reports, Volume 29

Supplemental Information

RAG-Mediated DNA Breaks Attenuate PU.1

Activity in Early B Cells through Activation of a SPIC-BCLAF1 Complex

Deepti Soodgupta, Lynn S. White, Wei Yang, Rachel Johnston, Jared M. Andrews, Masako Kohyama, Kenneth M. Murphy, Nima Mosammaparast, Jacqueline E. Payton, and Jeffrey J. Bednarski 
A.

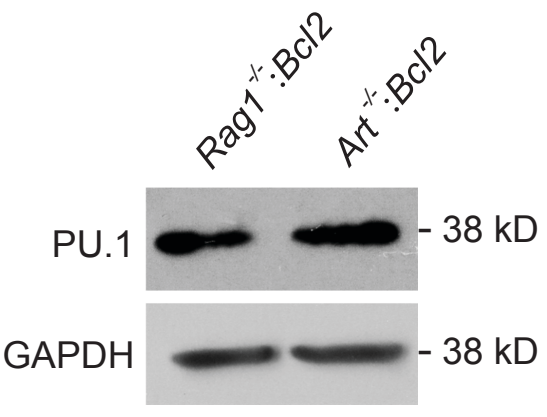

C.
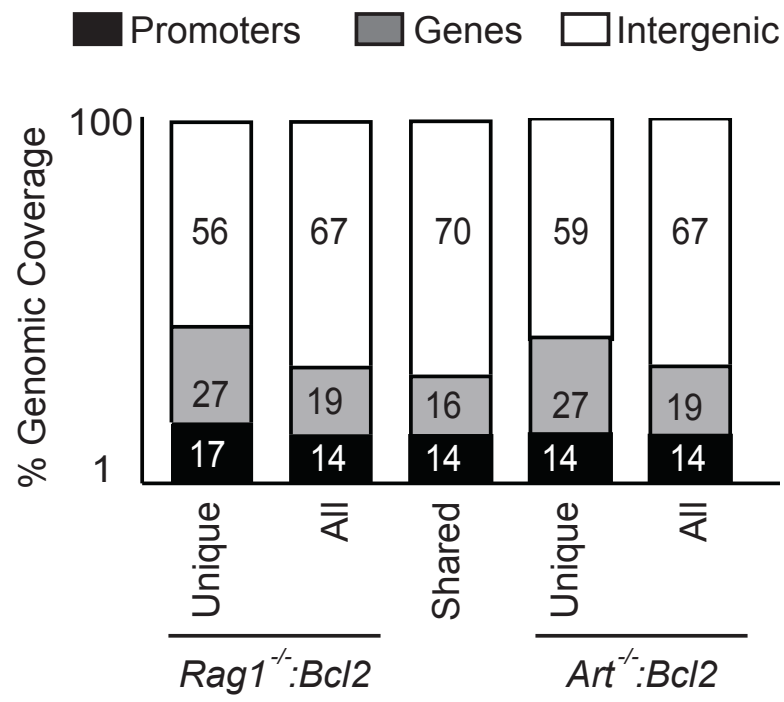

B.

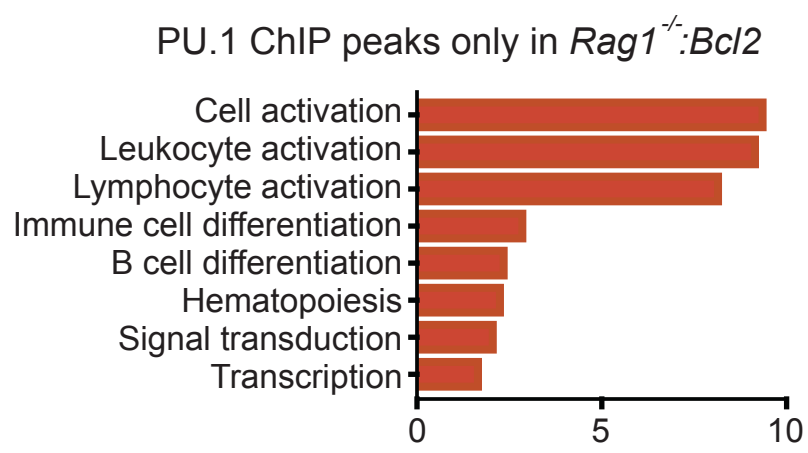

PU.1 ChIP peaks in $\operatorname{Rag}^{-1}: B c / 2$ and $A r t^{-1}: B C / 2$

Immune process. Lymhocyte homeostasis .

Lymphocyte activation.

Nuclear transport.

Apoptosis.

Signaling

DNA binding -

Cell Differentiation

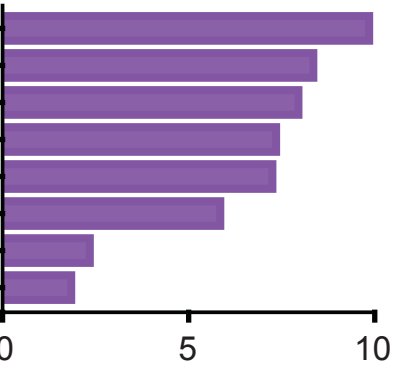

PU.1 peaks only in $A r t^{-/}: B c / 2$

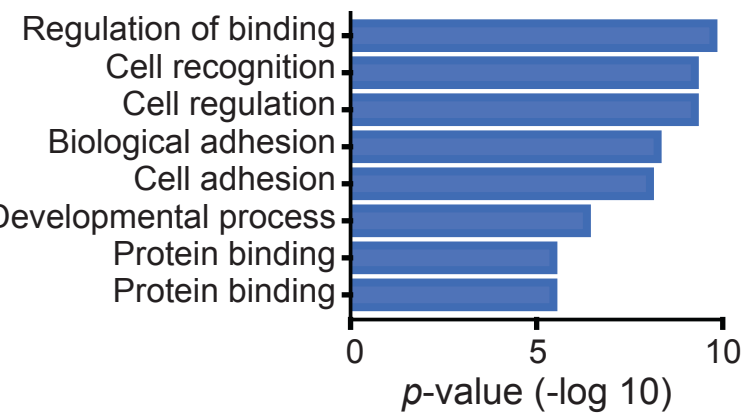

Figure S1. RAG DSBs do not alter PU.1 expression or distribution among genomic regions. Related to Figure 1. (A) Western blot of PU.1 levels in $\operatorname{Ragl}^{-/-}: B c l 2$ and $\mathrm{Art}^{-1-}: B c l 2$ abl pre-B cells treated with imatinib for 48 hours. Data are representative of three independent experiments. (B) Gene ontology analysis identifying the biological processes related to genes neighboring PU.1 ChIP-seq peaks from Figure 1B. (C) Graph depicting enrichment of PU.1 binding across genomic regions based on PU.1 ChIP-seq in Figure 1B. 
Figure S2
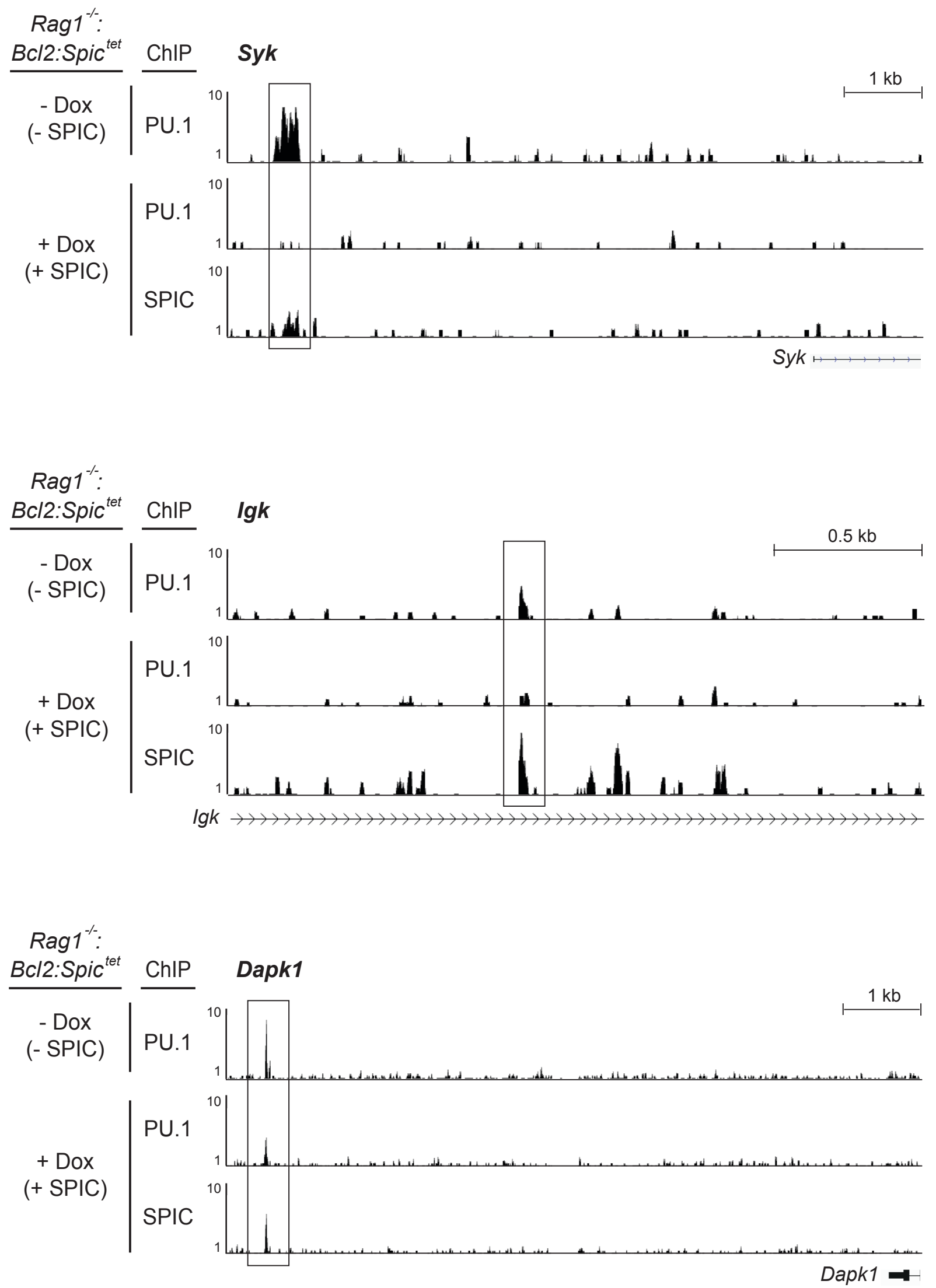

Figure S2. SPIC and PU.1 bind similar genomic regions. Related to Figure 3. Representative tracks for PU.1 and SPIC ChIP-seq at indicated positions from Figure 3B. ChIP-seq was performed as described in Figure 3B. 


\section{Figure S3}

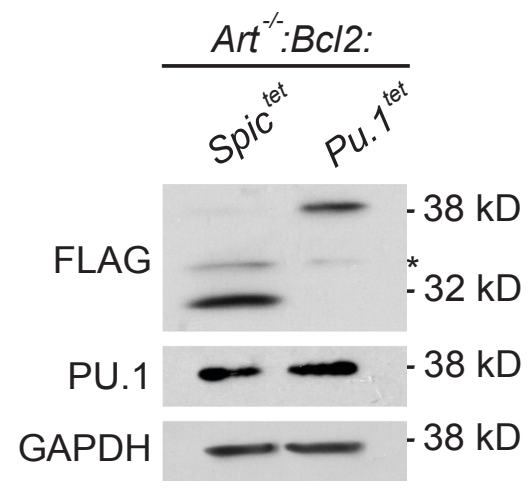

Figure S3. Inducible expression of SPIC and PU.1 in pre-B cells. Related to Figure 4. Western blot shows expression

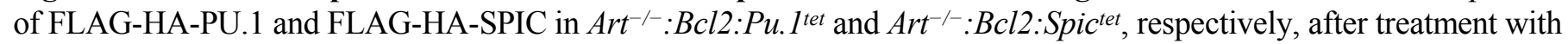
imatinib and $2 \mathrm{mM}$ doxycycline for 48 hours (as in Figure 4A). * indicates non-specific band. Data are representative of three independent experiments. 
A.
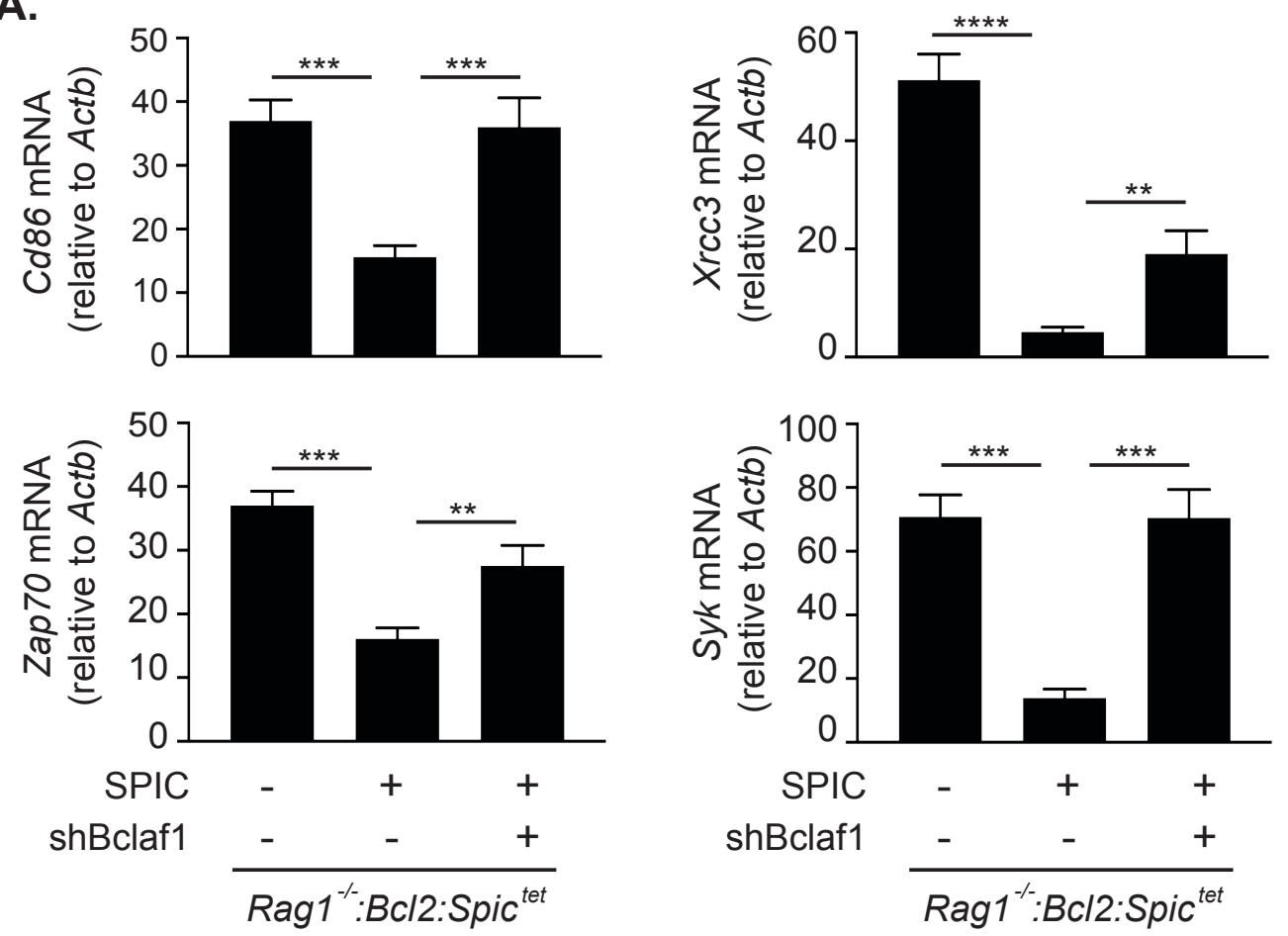

B. GO anaylsis of genes repressed by SPIC and rescued by BCLAF1 knockdown

\begin{tabular}{lc}
\hline \multicolumn{1}{c}{ Enriched Pathways } & $\boldsymbol{p}$-value (adj) \\
\hline Immune response & 0.00105 \\
Response to cytokine stimulus & 5.60 e-8 \\
B cell mediated immunity & 0.00105 \\
Negative regulation of migration & 0.00398 \\
\hline
\end{tabular}

Figure S4. SPIC and BCLAF1 regulate a gene expression in pre-B cells. Related to Figure 5. (A) RT-PCR validation of representative gene expression changes from Figure 5C. Data are mean and standard error for three independent experiments. ${ }^{* *} p$-value $\leq 0.01, * * * p$-value $\leq 0.001,{ }^{* * * *} p$-value $\leq 0.0001$. (B) Gene ontology analysis depicting immune and $\mathrm{B}$ cell function pathways related to genes from Figure $5 \mathrm{C}$ that are repressed upon SPIC induction in Rag1 $^{--}:$Bcl2:Spic ${ }^{\text {tet }}$ cells and rescued following BCLAF1 knockdown. 
Figure S5

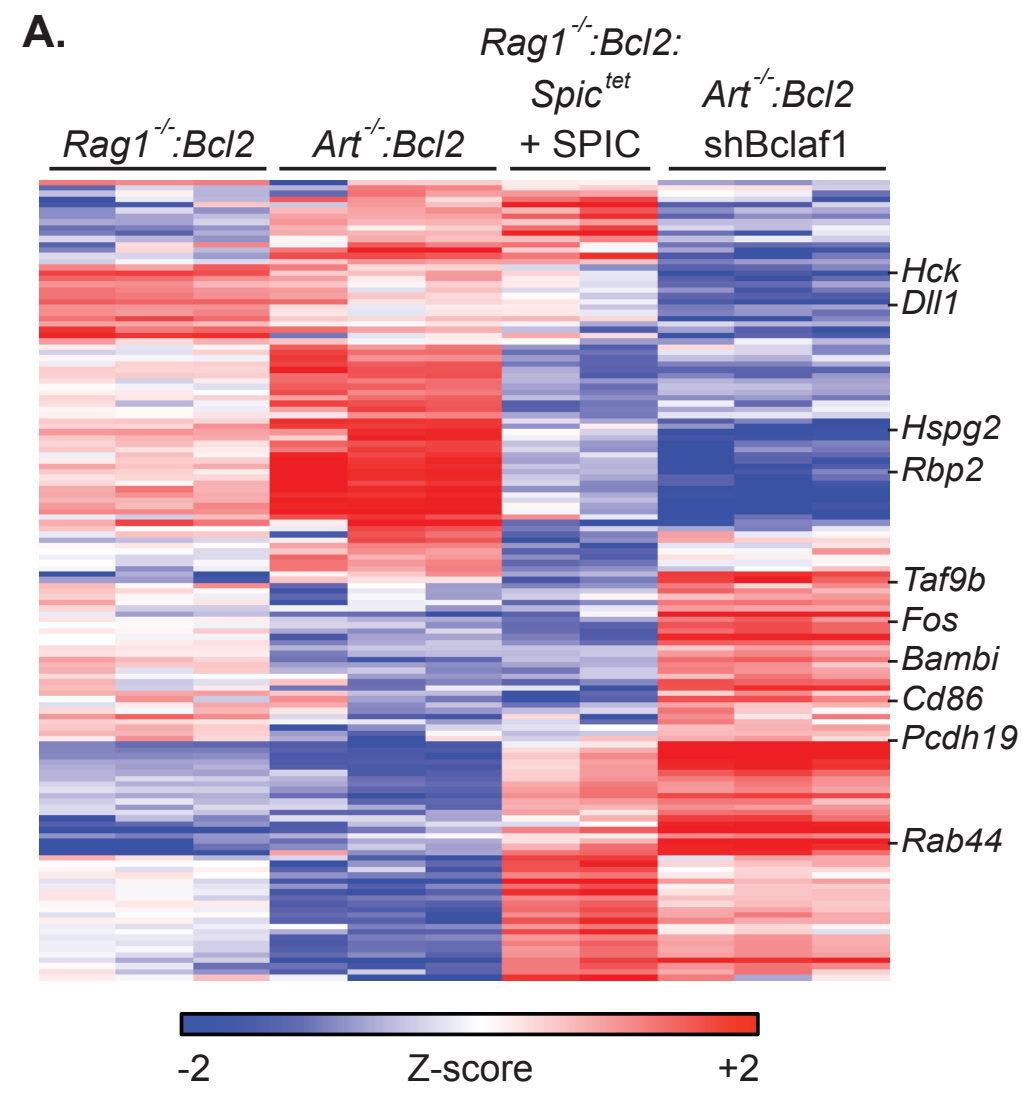

B. Anaylsis of genes in above heatmap

\begin{tabular}{lcr}
\hline \multicolumn{1}{c}{ Enriched Pathways } & \# genes & \multicolumn{1}{c}{ Genes } \\
\hline Cell cycle, growth and proliferation & 78 & Cd86, Hck \\
Cell adhesion & 24 & Pcdh19, Hspg2 \\
Apoptosis & 15 & Fos, Atf3 \\
Cellular component biogenesis & 14 & Taf9b, Dnm1 \\
RNA and protein localization & 13 & Rbp2, Rab44 \\
Immune response & 8 & Dll1, Fos \\
\hline
\end{tabular}

Figure S5. RAG DSBs, SPIC and BCLAF1 regulate a cohort of genes in pre-B cells. Related to Figure 5. (A) Heatmap of the 141 genes identified in Figure 5F. Cells were treated as in Figure 5C and 5E. (B) Gene ontology analysis depicting immune and $\mathrm{B}$ cell function pathways related to the 141 genes identified in the Figure 5F. Representative genes in each category are listed. All pathways have $p$-value $\leq 9.77 \times 10^{-5}$. 


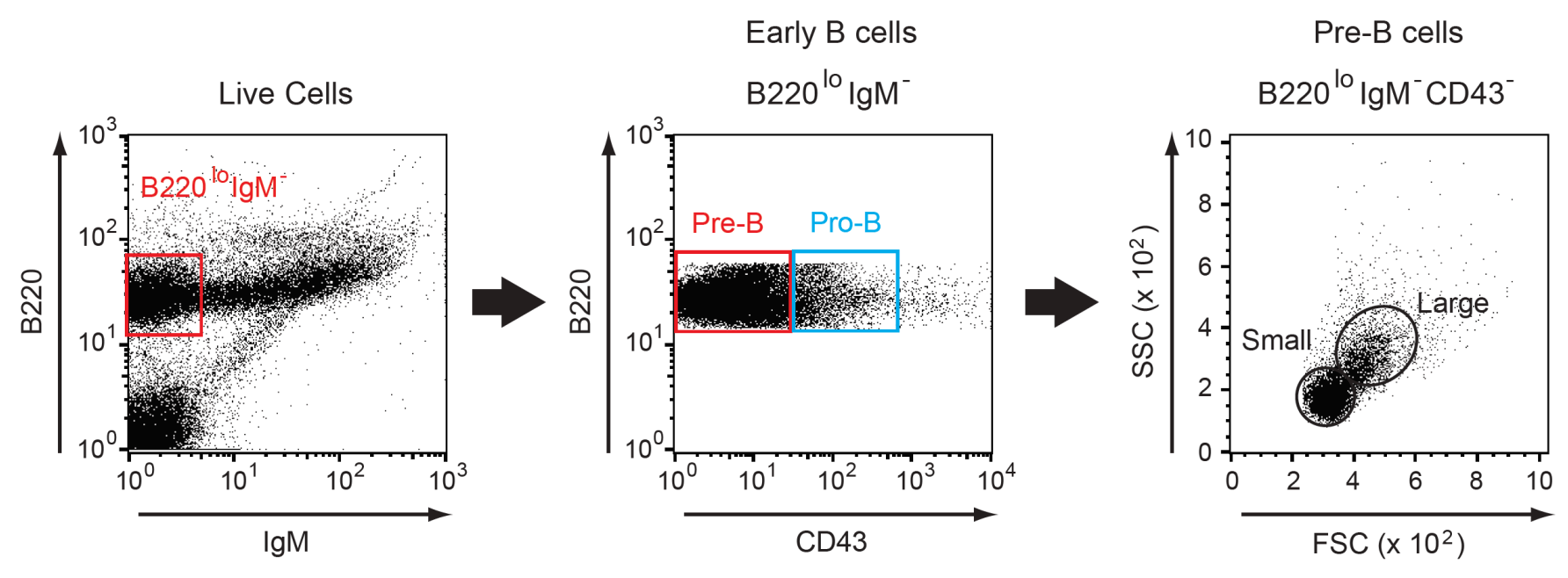

Figure S6. Analysis of bone marrow B cell populations. Related to Figure 7. Whole bone marrow was stained with B220, IgM and CD43 to quantify B cell populations as indicated. Data are representative of three independent experiments. 
Table S4. RAG DSBs, SPIC and BCLAF1 cooperatively regulate expression of a cohort of genes in pre-B cells. Related to Figure 5. Comparison of RAG DSB-dependent, SPIC-dependent, and BCLAF1-dependent gene expression changes from Table S2 and S3.

\begin{tabular}{cccccc}
\hline A2m11 & Frmd4b & Ppm1j & Ceacam9 & Lhfp14 & Sfmbt2 \\
AA467197 & Gh & Ptafr & Cfap70 & Lrr15 & Slc15a2 \\
Ackr2 & Gm14326 & Pygl & Clmn & Lrrc36 & Slc4a5 \\
Acot7 & Gnai1 & Rab11fip5 & Cntd1 & Lrrn4 & Slc5a11 \\
Aes & Gprasp2 & Rab44 & Col28a1 & Lyplal1 & Slc5a5 \\
Ahnak2 & H2-Aa & Rasgrp3 & Cpeb1 & Mcoln3 & Sncb \\
Angpt14 & H2-DMa & Rbp2 & Crhbp & Mfsd2a & Sntb1 \\
Ankrd37 & Hapln1 & Rgs1 & Crisp1 & Mmp14 & Spaca9 \\
Arrdc5 & Hck & Rgs11 & Ctla4 & Ms4a1 & Stac \\
Art5 & Hhatl & Rgs13 & Ctnnd2 & Myc & Steap4 \\
Atf3 & Hist1h2ae & Rimkla & Dll1 & Myh7 & Taf9b \\
Bambi & Hpn & Rpl3 & Dmpk & Nid2 & Tbxas1 \\
BC049352 & Hspg2 & Rps3a1 & Dnajc22 & Nkd1 & Tcaim \\
Bcat1 & Ifitm3 & Rsph1 & Dnm1 & Nox1 & Tdrd9 \\
C4bp & Igf2 & Rxra & Dpt & Npr2 & Tigit \\
Cabp1 & Il17f & Ryr3 & Dse & Nrxn3 & Tmprss4 \\
Cacnale & Il1rn & S100a4 & Dtx1 & Nxph4 & Tnfrsf9 \\
Cacna2d1 & Il2rb & Scd4 & Eda2r & Olfm1 & Tox \\
Capn11 & Iqgap2 & Scn11a & Etv5 & Otog & Trp73 \\
Ccnd2 & Itih3 & Sell & Fam129a & Paqr4 & Tsnaxip1 \\
Ccne1 & Kcnn4 & Serpina3f & Fcer2a & Pcdh19 & Uaca \\
Cd86 & Kctd14 & Serpina3g & Fgd4 & Pinlyp & \\
Fos & Pitpnm3 & Wfdc5 & Flrt1 & Uch11 & \\
Zan & Plekhg3 & Wnt10b & Pipox & Vldlr &
\end{tabular}


Table S5. Primer sequences. Related to STAR methods. List of primers used for genotyping, RT-PCR and ChIP-PCR.

\begin{tabular}{|c|c|c|}
\hline Primer Name & Application & Sequence \\
\hline Jk1_F & qRT PCR for DNA breaks & GCTACCCACTGCTCTGTTCC \\
\hline $\mathrm{Jk} 1 \_\mathrm{R}$ & qRT PCR for DNA breaks & CCTTGGAGAGTGCCAGAATC \\
\hline Syk_F & qRT PCR & TCTCTGCTGAGCTCCTAGCC \\
\hline Syk_R & qRT PCR & CAGAGGCCTCCACAGACTTC \\
\hline Spic_F & qRT PCR & TCTCTGCTGAGCTCCTAGCC \\
\hline Spic_R & qRT PCR & CAGAGGCCTCCACAGACTTC \\
\hline B-Actin_F & qRT PCR & AAACATTTCAAGACGCCATTGAC \\
\hline B-Actin_R & qRT PCR & СTCTGACGTGAGGATAAGGGT \\
\hline Xcrr3_- & qRT PCR & ATCCTTACGTGGCCTCCTTT \\
\hline Xcrr3_R & qRT PCR & TTGTCTGAGAGCTGCCTTGA \\
\hline Zap70_F & qRT PCR & TGGTACCTTTTGGCGGTGAAATG \\
\hline Zap70_R & qRT PCR & ATCTCCGGATCCTTCTGCAAT \\
\hline $\mathrm{Cd} 86[\mathrm{~F}$ & qRT PCR & GGGGTCTTCGACTGCCTGCG \\
\hline Cd86_R & qRT PCR & GCCTGGCTGATGATGGCCTGC \\
\hline Syk_CHIP_F & ChIP qRT PCR & GGGGAACTGAGCCCTAAAAG \\
\hline Syk_CHIP_R & ChIP qRT PCR & TATAGGGGCATGGGTGAGAG \\
\hline Dapk스_CHIP_F & ChIP qRT PCR & TCATAGCTACCGTCACACTG \\
\hline Dapk1_CHIP_R & ChIP qRT PCR & AACAGATGTGCCTAAGGTTC \\
\hline Cd200_CHIP_F & ChIP qRT PCR & GCTAGGATCAAAAGAATCCAGTC \\
\hline Cd200_CHIP_R & ChIP qRT PCR & GCTAGGATCAAAAGAATCCAGTC \\
\hline Sos2_CHIP_F & ChIP qRT PCR & TGAAGTTAGAGGGCCTGTCTG \\
\hline Sos2_CHIP_R & ChIP qRT PCR & AGGAAAGGAGGCAGCTTGAC \\
\hline Rag1_1 & Genotyping & AGAAGGAGAAGGATTCCTCAGAGGGG \\
\hline Rag1_2 & Genotyping & TTGGGAAGTAGACCTGACTGTGGG \\
\hline Rag1_3 & Genotyping & ACCGCTATCAGGAACATAGCGT \\
\hline $\operatorname{IgH}{ }_{-} \mathrm{F}$ & Genotyping & CAGGGTTATTGTCTCATGAGCGG \\
\hline $\operatorname{IgH} \mathrm{H}_{-}$ & Genotyping & САTТССТАССТССАСТСТGTСССТ \\
\hline $\mathrm{Bcl} 2 \_\mathrm{F}$ & Genotyping & CGAGATGTCCAGCCAGCTGCACCTG \\
\hline $\mathrm{Bcl} 2 \_\mathrm{R}$ & Genotyping & TCACTTGTGGCCCAGATAGGCACCCA \\
\hline Art_1 & Genotyping & CAAGAGGCATTCGTGTATATGGGTGGC \\
\hline Art_2 & Genotyping & CCCGTAACAGAGCTATGACAGGACCGGG \\
\hline Art_3 & Genotyping & ACCCCAGGCATATCTGTCACCCC \\
\hline $\mathrm{Mb} 1 \mathrm{Cre} \_\mathrm{F}$ & Genotyping & CATTTTCGAGGGAGCTTCA \\
\hline Mb1 Cre_R & Genotyping & ACTGAGGCAGGAGGATTGG \\
\hline Bcalfl_1 & Genotyping & AGACTTGGTAACACATACCTGTAATCCC \\
\hline Bcalf1_2 & Genotyping & ACTAACACATCCAAATTTTAAGAGCTCC \\
\hline Bcalf1_3 & Genotyping & AGCAGAAACTATACTGCCAAGAGTTGC \\
\hline FlpE_F & Genotyping & ACTCCGTTAGGCCCTTCATT \\
\hline FlpE_R & Genotyping & GCGCCTTATTCAATCTTTGC \\
\hline
\end{tabular}

